NBER WORKING PAPER SERIES

\title{
ROUGHING IT UP: INCLUDING JUMP COMPONENTS IN THE MEASUREMENT, MODELING AND FORECASTING OF RETURN VOLATILITY
}

\author{
Torben G. Andersen \\ Tim Bollerslev \\ Francis X. Diebold \\ Working Paper 11775 \\ http://www.nber.org/papers/w11775 \\ NATIONAL BUREAU OF ECONOMIC RESEARCH \\ 1050 Massachusetts Avenue \\ Cambridge, MA 02138 \\ November 2005
}

Earlier versions of this paper were circulated under the title "Some Like it Smooth, and Some Like it Rough: Disentangling Continuous and Jump Components in Measuring, Modeling and Forecasting Asset Return Volatility." Our research was supported by the National Science Foundation, the Guggenheim Foundation, and the Wharton Financial Institutions Center. We are grateful to Olsen and Associates for generously supplying their intraday exchange rate data. Xin Huang provided excellent research assistance. We would also like to thank Federico Bandi, Michael Johannes, Neil Shephard, George Tauchen, and two anonymous referees for helpful comments, as well as seminar participants at the NBER/NSF Time Series Conference, the Montreal Realized Volatility Conference, the Academia Sinica Conference on Analysis of HighFrequency Financial Data and Market Microstructure, the Erasmus University Rotterdam Journal of Applied Econometrics Conference, the Aarhus Econometrics Conference, the Seoul Far Eastern Meetings of the Econometric Society, the Portland Annual Meeting of the Western Finance Association, the NBER Summer Institute, and the NYU Innovations in Financial Econometrics Conference, as well as Baruch College, Nuffield College, Princeton, Toronto, UCLA, Wharton, and Uppsala Universities. The views expressed herein are those of the author(s) and do not necessarily reflect the views of the National Bureau of Economic Research.

(C)2005 by Torben G. Andersen, Tim Bollerslev, and Francis X. Diebold. All rights reserved. Short sections of text, not to exceed two paragraphs, may be quoted without explicit permission provided that full credit, including $($ ) notice, is given to the source. 
Roughing it Up: Including Jump Components in the Measurement, Modeling and Forecasting of Return Volatility

Torben G. Andersen, Tim Bollerslev, and Francis X. Diebold

NBER Working Paper No. 11775

November 2005

JEL No. C1, G1

\begin{abstract}
A rapidly growing literature has documented important improvements in financial return volatility measurement and forecasting via use of realized variation measures constructed from high-frequency returns coupled with simple modeling procedures. Building on recent theoretical results in Barndorff-Nielsen and Shephard (2004a, 2005) for related bi-power variation measures, the present paper provides a practical and robust framework for non-parametrically measuring the jump component in asset return volatility. In an application to the $\mathrm{DM} / \$$ exchange rate, the S\&P500 market index, and the 30-year U.S. Treasury bond yield, we find that jumps are both highly prevalent and distinctly less persistent than the continuous sample path variation process. Moreover, many jumps appear directly associated with specific macroeconomic news announcements. Separating jump from non-jump movements in a simple but sophisticated volatility forecasting model, we find that almost all of the predictability in daily, weekly, and monthly return volatilities comes from the non-jump component. Our results thus set the stage for a number of interesting future econometric developments and important financial applications by separately modeling, forecasting, and pricing the continuous and jump components of the total return variation process.

\begin{tabular}{|c|c|c|}
\hline Torben G. Andersen & Tim Bollerslev & Francis X. Diebold \\
\hline Kellogg School of Management & Department of Economics & Department of Economics \\
\hline Northwestern University & Duke University & University of Pennsylvania \\
\hline 2001 Sheridan Road & Box 90097 & 3718 Locust Walk \\
\hline $\begin{array}{l}\text { Evanston, IL } 60208 \\
\text { and NBER }\end{array}$ & $\begin{array}{l}\text { Durham, NC 27708-0097 } \\
\text { and NBER }\end{array}$ & $\begin{array}{l}\text { Philadelphia, PA 19104-6297 } \\
\text { and NBER }\end{array}$ \\
\hline t-anderson@kellogg.northwest & boller@econ.c & fdiebold@sas.upenn.edu \\
\hline
\end{tabular}
\end{abstract}




\section{Introduction}

Volatility is central to asset pricing, asset allocation, and risk management. In contrast to the estimation of expected returns, which generally requires long time spans of data, the results of Merton (1980) and Nelson (1992) suggest that volatility may be estimated arbitrarily well through the use of sufficiently finely sampled high-frequency returns over any fixed time interval. However, the assumption of a continuous sample path diffusion underlying the theoretical results is invariably violated in practice. Thus, despite the increased availability of high-frequency data for a host of different financial instruments, practical complications have hampered the implementation of direct high-frequency volatility modeling and filtering procedures. ${ }^{1}$

In response, Andersen and Bollerslev (1998), Andersen, Bollerslev, Diebold and Labys (2001) (henceforth ABDL), Barndorff-Nielsen and Shephard (2002a,b), and Meddahi (2002), among others, have recently advocated the use of non-parametric realized volatility, or variation, measures to conveniently circumvent the data complications while retaining most of the relevant information in the intraday data for measuring, modeling and forecasting volatilities over daily and longer horizons. Indeed, the empirical results in ABDL (2003) strongly suggest that simple models of realized volatility outperform the popular GARCH and related stochastic volatility models in out-of-sample forecasting. ${ }^{2}$

At the same time, recent parametric studies have suggested the importance of explicitly allowing for jumps, or discontinuities, in the estimation of specific stochastic volatility models and in the pricing of options and other derivatives. ${ }^{3}$ In particular, it appears that many $(\log )$ price processes are best described by a combination of a smooth and very slowly mean-reverting continuous sample path process and a much less persistent jump component. ${ }^{4}$ Thus far, however, the non-parametric realized volatility literature has paid comparatively little attention to jumps, and related, to distinguishing jump from non-jump movements.

Set against this backdrop, in the present paper we seek to further advance the nonparametric realized volatility approach through the development of a practical non-parametric procedure for separately measuring the continuous sample path variation and the discontinuous jump part of the quadratic variation process. Our approach builds directly on the new theoretical results in Barndorff-Nielsen and Shephard (2004a, 2005)

\footnotetext{
${ }^{1}$ See, among others, Aït-Sahalia, Mykland and Zhang (2005), Andersen, Bollerslev and Diebold (2005), Engle (2000), Russell and Engle (2005), and Rydberg and Shephard (2003).

2 These empirical findings are further corroborated by the analytical results for specific stochastic volatility models reported in Andersen, Bollerslev and Meddahi (2004).

${ }^{3}$ See, among others, Andersen, Benzoni and Lund (2002), Bates (2000), Chan and Maheu (2002), Chernov, Gallant, Ghysels, and Tauchen (2003), Drost, Nijman and Werker (1998), Eraker (2004), Eraker, Johannes and Polson (2003), Johannes (2004), Johannes, Kumar and Polson (1999), Maheu and McCurdy (2004), Khalaf, Saphores and Bilodeau (2003), and Pan (2002).

${ }^{4}$ Earlier influential work on homoskedastic jump-diffusions includes Merton (1976), Ball and Torous (1983), Beckers (1981), and Jarrow and Rosenfeld (1984). More recently, Jorion (1988) and Vlaar and Palm (1993) incorporated jumps in the estimation of discrete-time ARCH and GARCH models. See also the discussion in Das (2002).
} 
involving so-called bi-power variation measures constructed from the summation of appropriately scaled crossproducts of adjacent high-frequency absolute returns. ${ }^{5}$ Implementing these ideas empirically with more than a decade of five-minute high-frequency returns for the DM/\$ foreign exchange market, the S\&P500 market index, and the 30-year U.S. Treasury yield, we shed new light on the dynamics and comparative magnitudes of jumps across the different markets. We also demonstrate important gains in terms of volatility forecast accuracy by explicitly differentiating the jump and continuous sample path components. These gains obtain at daily, weekly, and even monthly forecast horizons. Our new HAR-RV-CJ forecasting model incorporating the jumps builds directly on the heterogenous AR model for the realized volatility, or HAR-RV model, due to Müller et al. (1997) and Corsi (2003), in which the realized volatility is parameterized as a linear function of the lagged realized volatilities over different horizons.

The paper proceeds as follows. In the next section we briefly review the relevant bi-power variation theory. In Section III we describe our high-frequency data, extract a preliminary measure of jumps, and describe their features. In Section IV we describe the HAR-RV volatility forecasting model, modify it to allow and control for jumps (producing our HAR-RV-J model), and assess its empirical performance. In Section V we significantly refine the jump estimator by shrinking it toward zero in a fashion motivated by recentlydeveloped powerful asymptotic theory, and by robustifying it to market microstructure noise (as motivated by the extensive simulation evidence in Huang and Tauchen, 2005). We then illustrate that many of the jumps so identified are associated with macroeconomic news. In Section VI we build a more refined model that makes full use our refined jump estimates by incorporating jump and non-jump components separately. The new model (HAR-RV-CJ) includes the earlier HAR-RV-J as a special and potentially restrictive case and produces additional forecast enhancements. We conclude in Section VII with several suggestions for future research.

\section{Theoretical Framework}

Let $p(t)$ denote a logarithmic asset price at time $t$. The continuous-time jump diffusion process traditionally used in asset pricing is conveniently expressed in stochastic differential equation (sde) form as

$$
d p(t)=\mu(t) d t+\sigma(t) d W(t)+\kappa(t) d q(t), \quad 0 \leq t \leq T
$$

where $\mu(t)$ is a continuous and locally bounded variation process, $\sigma(t)$ is a strictly positive stochastic volatility process with a sample path that is right continuous and has well defined left limits (allowing for occasional

\footnotetext{
5 This approach is distinctly different from the recent work of Aï-Sahalia (2002), who relies on direct estimates of the transition density function.
} 
jumps in volatility), $W(t)$ is a standard Brownian motion, and $q(t)$ is a counting process with (possibly) timevarying intensity $\lambda(t)$. That is, $P[d q(t)=1]=\lambda(t) d t$, where $\kappa(t) \equiv p(t)-p(t$-) refers to the size of the corresponding discrete jumps in the logarithmic price process. The quadratic variation for the cumulative return process, $r(t)$ $\equiv p(t)-p(0)$, is then

$$
[r, r]_{t}=\int_{0}^{t} \sigma^{2}(s) d s+\sum_{0<s \leq t} \kappa^{2}(s),
$$

where by definition the summation consists of the $q(t)$ squared jumps that occurred between time 0 and time $t$. Of course, in the absence of jumps, or $q(t) \equiv 0$, the summation vanishes and the quadratic variation simply equals the integrated volatility of the continuous sample path component.

Several recent studies concerned with the direct estimation of continuous time stochastic volatility models have highlighted the importance of explicitly incorporating jumps in the price process along the lines of equation (1). ${ }^{6}$ Moreover, the specific parametric model estimates reported in this literature have generally suggested that any dynamic dependence in the size or occurrence of the jumps is much less persistent than the dependence in the continuous sample path volatility process. Here we take a complementary non-parametric approach, squarely in the tradition of the realized volatility literature but specifically distinguishing jump from non-jump movements, relying on both the recent emergence of high-frequency data and powerful asymptotic theory.

\section{A. High-Frequency Data, Bi-Power Variation, and Jumps}

Let the discretely sampled $\Delta$-period returns be denoted by, $r_{t, \Delta} \equiv p(t)-p(t-\Delta)$. For ease of notation we normalize the daily time interval to unity and label the corresponding discretely sampled daily returns by a single time subscript, $r_{t+1} \equiv r_{t+1,1}$. Also, we define the daily realized volatility, or variation, by the summation of the corresponding $1 / \Delta$ high-frequency intradaily squared returns, ${ }^{7}$

$$
R V_{t+1}(\Delta) \equiv \sum_{j=1}^{1 / \Delta} r_{t+j \cdot \Delta, \Delta}^{2},
$$

where for notational simplicity and without loss of generality $1 / \Delta$ is assumed to be an integer. Then, as emphasized in Andersen and Bollerslev (1998), ABDL (2001), Barndorff-Nielsen and Shephard (2002a,b), and

\footnotetext{
${ }^{6}$ See, among others, Andersen, Benzoni and Lund (2002), Eraker, Johannes and Polson (2003), Eraker (2004), Johannes (2004), and Johannes, Kumar and Polson (1999).

${ }^{7}$ We will use the terms realized volatility and realized variation interchangeably.
} 
Comte and Renault (1998), among others, it follows directly by the theory of quadratic variation that the realized variation converges uniformly in probability to the increment of the quadratic variation process as the sampling frequency of the underlying returns increases. That is,

$$
R V_{t+1}(\Delta) \rightarrow \int_{t}^{t+1} \sigma^{2}(s) d s+\sum_{t<s \leq t+1} \kappa^{2}(s),
$$

for $\Delta \rightarrow 0$. Thus, in the absence of jumps the realized variation is consistent for the integrated volatility that figures prominently in the stochastic volatility option pricing literature. This result, in part, motivates the modeling and forecasting procedures for realized volatilities advocated in ABDL (2003). It is clear, however, that in general the realized volatility will inherit the dynamics of both the continuous sample path process and the jump process. Although this does not impinge upon the theoretical justification for directly modeling and forecasting $R V_{t+1}(\Delta)$ through simple procedures that do not distinguish jump and non-jump contributions to volatility, it does suggest that superior forecasting models may be constructed by separately measuring and modeling the two components in equation (4).

Building on this intuition, the present paper seeks to improve on the predictive models developed in ABDL (2003) through the use of new and powerful asymptotic results (for $\Delta \rightarrow 0$ ) of Barndorff-Nielsen and Shephard (2004a, 2005) that allow for separate (non-parametric) identification of the two components of the quadratic variation process. Specifically, define the standardized realized bi-power variation as

$$
B V_{t+1}(\Delta) \equiv \mu_{1}^{-2} \sum_{j=2}^{1 / \Delta}\left|r_{t+j \cdot \Delta, \Delta}\right|\left|r_{t+(j-1) \cdot \Delta, \Delta}\right|,
$$

where $\mu_{1} \equiv \sqrt{ }(2 / \pi)=E(|Z|)$ denotes the mean of the absolute value of standard normally distributed random variable, $\mathrm{Z}$. It is then possible to show that for $\Delta \rightarrow 0,{ }^{8}$

$$
B V_{t+1}(\Delta) \rightarrow \int_{t}^{t+1} \sigma^{2}(s) d s
$$

\footnotetext{
${ }^{8}$ Corresponding general asymptotic results for so-called realized power variation measures have recently been established by Barndorff-Nielsen and Shephard (2003, 2004a); see also Barndorff-Nielsen, Graversen and Shephard (2004) for a survey of related results. In particular, it follows that in general for $0<p<2$ and $\Delta \rightarrow 0$,

$$
R P V_{t+1}(\Delta, p) \equiv \mu_{p}^{-1} \Delta^{1-p / 2} \sum_{j=1}^{1 / \Delta}\left|r_{t+j \cdot \Delta, \Delta}\right|^{p} \rightarrow \int_{t}^{t+1} \sigma^{p}(s) d s,
$$

where $\mu_{p} \equiv 2^{p / 2} \Gamma(1 / 2(p+1)) / \Gamma(1 / 2)=E\left(|Z|^{p}\right)$. Hence, the impact of the discontinuous jump process disappears in the limit for the power variation measures with $0<p<2$. In contrast, $R P V_{t+1}(\Delta, p)$ diverges to infinity for $p>2$, while $R P V_{t+1}(\Delta, 2) \equiv R V_{t+1}(\Delta)$ converges to the integrated volatility plus the sum of the squared jumps, as in equation (4). Related expressions for the conditional moments of different powers of absolute returns have also been utilized by Aitt-Sahalia (2004) in the formulation of a GMM-type estimator for specific parametric homoskedastic jump-diffusion models.
} 
Hence, as first noted by Barndorff-Nielsen and Shephard (2004a), combining the results in equations (4) and (6), the contribution to the quadratic variation process due to the discontinuities (jumps) in the underlying price process may be consistently estimated (for $\Delta \rightarrow 0$ ) by

$$
R V_{t+1}(\Delta)-B V_{t+1}(\Delta) \rightarrow \sum_{t<s \leq t+1} \kappa^{2}(s)
$$

This is the central insight on which the theoretical and empirical results of this paper build.

Of course, nothing prevents the estimates of the squared jumps defined by the right hand-side of (7) from becoming negative in a given finite $(\Delta>0)$ sample. Thus, following the suggestion of Barndorff-Nielsen and Shephard (2004a), we truncate the actual empirical measurements at zero,

$$
J_{t+1}(\Delta) \equiv \max \left[R V_{t+1}(\Delta)-B V_{t+1}(\Delta), 0\right]
$$

to ensure that all of the daily estimates are non-negative.

\section{Data and Summary Statistics}

To highlight the generality of our empirical results related to the improved forecasting performance obtained by separately measuring the contribution to the overall variation coming from the discontinuous price movements, we present the results for three different markets. We begin this section with a brief discussion of the data sources, followed by a summary of the most salient features of the resulting realized volatility and jump series for each of three markets.

\section{A Data Description}

We present the results for three markets: the foreign exchange spot market (DM/\$), the equity futures market (U.S. S\&P 500 index), and the interest rate futures market (30-year U.S. Treasury yield). The DM/\$ volatilities range from December 1986 through June 1999, for a total of 3,045 daily observations. The underlying high-frequency spot quotations were kindly provided by Olsen \& Associates in Zurich, Switzerland. This same series has been previously analyzed in $\operatorname{ABDL}(2001,2003)$. The S\&P500 volatility measurements are based on tick-by-tick transactions prices from the Chicago Mercantile Exchange (CME) augmented with overnight prices from the GLOBEX automated trade execution system, from January 1990 through December 2002. The T-bond volatilities are similarly constructed from tick-by-tick transactions prices for the 30 year U.S. Treasury Bond futures contract traded on the Chicago Board of Trade (CBOT), again from January 1990 
through December 2002. After removing holidays and other inactive trading days, we have a total of 3,213 observations for each of the two futures markets. ${ }^{9}$ A more detailed description of the S\&P and T-bond data is available in Andersen, Bollerslev, Diebold and Vega (2005), where the same high-frequency data are analyzed from a very different perspective. All of the volatility measures are based on linearly interpolated logarithmic five-minute returns, as in Müller et al. (1990) and Dacorogna et al. (1993). ${ }^{10}$ For the foreign exchange market this results in a total of $1 / \Delta=288$ high-frequency return observations per day, while the two futures contracts are actively traded for $1 / \Delta=97$ five-minute intervals per day. For notational simplicity, we omit the explicit reference to $\Delta$ in the following, referring to the five-minute realized volatility and jump measures defined by equations (3) and (8) as $R V_{t}$ and $J_{t}$, respectively.

\section{B. Realized Volatilities and Jumps}

The first panels in Figures 1A-C show the resulting three daily realized volatility series in standard deviation form, or $R V_{t}^{1 / 2}$. Each of the three series clearly exhibits a high degree of own serial correlation. This is confirmed by the Ljung-Box statistics for up to tenth order serial correlation reported in Tables 1A-C equal to $5,714,12,184$, and 1,718 , respectively. Similar results obtain for the realized variances and logarithmic transformations reported in the first and third columns in the tables. Comparing the volatility across the three markets, the S\&P500 returns are the most volatile, followed by the exchange rate returns. Also, consistent with earlier evidence for the foreign exchange market in ABDL (2001), and related findings for individual stocks in Andersen, Bollerslev, Diebold and Ebens (2002) and the S\&P500 in Deo, Hurvich and Lu (2005) and Martens, van Dijk and Pooter (2004), the logarithmic standard deviations are generally much closer to being normally distributed than are the raw realized volatility series. Hence, from a modeling perspective, the logarithmic realized volatilities are more amenable to the use of standard time series procedures. ${ }^{11}$

The second panels in Figures 1A-C display the separate measurements of the jump components (again

9 We explicitly exclude all days with sequences of more than twenty consecutive five-minute intervals of no new prices for the S\&P500, and forty consecutive five-minute intervals of no new prices for the T-bond market.

10 To mitigate the impact of market microstructure frictions in the construction of unbiased and efficient realized volatility measurements, a number of recent studies have proposed ways of "optimally" choosing $\Delta$ (e.g., Ait-Sahalia, Mykland and Zhang, 2005; Bandi and Russell, 2004a,b), sub-sampling schemes (e.g., Zhang, Aït-Sahalia and Mykland, 2005; Zhang, 2004), pre-filtering (e.g., Andreou and Ghysels, 2002; Areal and Taylor, 2002; Bollen and Inder, 2002; Corsi, Zumbach, Müller and Dacorogna, 2001; Oomen 2002, 2004), Fourier methods (Barucci and Reno, 2002; and Malliavin and Mancino, 2002), or other kernel type estimators (e.g., Barndorff-Nielsen, Hansen, Lunde and Shephard, 2004; Hansen and Lunde 2006; and Zhou, 1996). For now we simply follow ABDL $(2002,2001)$, along with most of the existing empirical literature, in the use of unweighted fiveminute returns for each of the three actively traded markets analyzed here. However, we will return to a more detailed discussion of the market microstructure issue and pertinent jump measurements in Section V below.

${ }^{11}$ Modeling and forecasting log volatility also has the virtue of automatically imposing non-negativity of fitted and forecasted volatilities. 
in standard deviation form) based on the truncated estimator in equation (8). ${ }^{12}$ As is evident from the figures, many of the largest realized volatilities are directly associated with jumps in the underlying price process. Some of the largest jumps in the DM/\$ market occurred during the earlier 1986-88 part of the sample, while the size of the jumps for the S\&P500 has increased significantly over the most recent 2001-02 period. In contrast, the size of the jumps in the T-Bond market seem to be much more evenly distributed throughout the sample. Overall, both the size and occurrence of jumps appear to be much more predictable for the S\&P500 than for the other two markets.

These visual observations are readily confirmed by the standard Ljung-Box portmanteau statistics for up to tenth order serial correlation in the $J_{t}, J_{t}^{1 / 2}$, and $\log \left(J_{t}+1\right)$ series reported in the last three columns in Tables 1A-C. It is noteworthy that although the Ljung-Box statistics for the jumps are generally significant at conventional significance levels (especially for the jumps expressed in standard deviation or logarithmic form), the actual values are markedly lower than the corresponding test statistics for the realized volatility series reported in the first three columns. This indicates decidedly less own dynamic dependence in the portion of the overall quadratic variation originating from the discontinuous sample path price process compared to the dynamic dependence in the continuous sample path price movements. The numbers in the table also indicate that the jumps are relatively least important for the DM/\$ market, with the mean of the $J_{t}$ series accounting for 0.072 of the mean of $R V_{t}$, while the same ratios for the S\&P500 and T-bond markets equal 0.144 and 0.126 , respectively.

Motivated by these observations, we now put the idea of separately measuring the jump component to work in the construction of new and simple-to-implement realized volatility forecasting models. More specifically, we follow ABDL (2003) in directly estimating a set of time series models for each of the different realized volatility measures in Tables $1 \mathrm{~A}-\mathrm{C}$; i.e., $R V_{t}, R V_{t}^{1 / 2}$, and $\log \left(R V_{t}\right)$. Then, in order to assess the added value of separately measuring the jump component in forecasting the realized volatilities, we simply include the raw $J_{t}, J_{t}^{1 / 2}$, and $\log \left(J_{t}+1\right)$ jump series as additional explanatory variables in the various forecasting regressions.

\section{Accounting for Jumps in Realized Volatility Modeling and Forecasting}

A number of empirical studies have argued for the importance of long-memory dependence in financial market volatility. Several different parametric ARCH and stochastic volatility formulations have also been

\footnotetext{
12 The difference between the daily realized variation and bi-power variation measures result in negative estimates for the squared daily jumps on 30.6, 27.9 and 18.3 percent of the days for each of the three markets, respectively. As discussed below, in the absence of jumps, the difference should be negative asymptotically $(\Delta \rightarrow 0)$ for half of the days in the sample.
} 
proposed in the literature for capturing this phenomenon (e.g., Andersen and Bollerslev, 1997; Baillie, Bollerslev, and Mikkelsen, 1996; Breidt, Crato and de Lima, 1998; Dacorogna et al., 2001; Ding, Granger and Engle, 1993; Robinson, 1991). These same empirical observations have similarly motivated the estimation of long-memory type ARFIMA models for realized volatilities in ABDL (2003), Areal and Taylor (2002), Deo, Hurvich and Lu (2005), Koopman, Jungbacker and Hol (2005), Martens, van Dijk, and Pooter (2004), Oomen (2002), Pong, Shackleton, Taylor and Xu (2004), and Thomakos and Wang (2003), among others.

Here we eschew such complicated fractionally integrated long-memory formulations and rely instead on the simple-to-estimate HAR-RV class of volatility models proposed by Corsi (2003). The HAR-RV formulation is based on a straightforward extension of the so-called Heterogeneous ARCH, or HARCH, class of models analyzed by Müller et al. (1997), in which the conditional variance of the discretely sampled returns is parameterized as a linear function of the lagged squared returns over the identical return horizon together with the squared returns over longer and/or shorter return horizons. ${ }^{13}$ Although the HAR structure does not formally possess long-memory, the mixing of relatively few volatility components is capable of reproducing a remarkably slow volatility autocorrelation decay that is almost indistinguishable from that of a hyperbolic (long-memory) pattern over most empirically relevant forecast horizons. ${ }^{14}$

\section{A. The HAR-RV-J Model}

To define the HAR-RV model, let the multi-period normalized realized variation, defined by the sum of the corresponding one-period measures, be denoted by,

$$
R V_{t, t+h}=h^{-1}\left[R V_{t+1}+R V_{t+2}+\ldots+R V_{t+h}\right]
$$

where $h=1,2, \ldots$. Note that, by definition $R V_{t, t+1} \equiv R V_{t+1}$. Also, provided that the expectations exist, $E\left(R V_{t, t+h}\right) \equiv E\left(R V_{t+1}\right)$ for all $h$. For ease of reference, we will refer to these normalized measures for $h=5$ and $h=22$ as the weekly and monthly volatilities, respectively. The daily HAR-RV model of Corsi (2003) may then

\footnotetext{
13 Müller et al. (1997) heuristically motivate the HARCH model through the existence of distinct groups of traders with different investment horizons.

14 Mixtures of low-order ARMA models have similarly been used in approximating and forecasting long-memory dependence in the conditional mean by Basak, Chan and Palma (2001), Cox (1991), Hsu and Breidt (2003), Man (2003), O'Connell (1971) and Tiao and Tsay (1994), among others. The component GARCH model in Engle and Lee (1999) and the multi-factor continuous time stochastic volatility model in Gallant, Hsu and Tauchen (1999) are both motivated by similar considerations; see also the discussion of the related multifractal regime switching models in Calvet and Fisher (2001, 2002).
} 
be expressed as, ${ }^{15}$

$$
R V_{t+1}=\beta_{0}+\beta_{D} R V_{t}+\beta_{W} R V_{t-5, t}+\beta_{M} R V_{t-22, t}+\epsilon_{t+1},
$$

where $t=1,2, \ldots, T$. Of course, realized volatilities over other horizons could easily be included as additional explanatory variables on the right-hand-side of the regression equation, but the daily, weekly and monthly measures employed here afford a natural economic interpretation. ${ }^{16}$

This HAR-RV model for one-day volatilities extends straightforwardly to longer horizons, $R V_{t, t+h}$. Moreover, given the separate non-parametric measurements of the jump component discussed above, the corresponding time series is readily included as an additional explanatory variable, resulting in the new HARRV-J model,

$$
R V_{t, t+h}=\beta_{0}+\beta_{D} R V_{t}+\beta_{W} R V_{t-5, t}+\beta_{M} R V_{t-22, t}+\beta_{J} J_{t}+\epsilon_{t, t+h} .
$$

With observations every period and longer forecast horizons, or $h>1$, the error term will generally be serially correlated up to (at least) order $h-1$. This will not affect the consistency of the regression coefficient estimates, but the corresponding standard errors of the estimates obviously need to be adjusted. In the results discussed below, we rely on the Bartlett/Newey-West heteroskedasticity consistent covariance matrix estimator with 5, 10, and 44 lags for the daily $(h=1)$, weekly $(h=5)$, and monthly $(h=22)$ regression estimates, respectively.

Turning to the results reported in the first three columns in Tables $2 \mathrm{~A}-\mathrm{C}$, the estimates for $\beta_{D}, \beta_{W}$, and $\beta_{M}$ confirm the existence of highly persistent volatility dependence. Interestingly, the relative importance of the daily volatility component decreases from the daily to the weekly to the monthly regressions, whereas the monthly volatility component tends to be relatively more important for the longer-run monthly regressions. Importantly, the estimates of the jump component, $\beta_{J}$, are systematically negative across all models and markets, and with few exceptions, overwhelmingly significant. ${ }^{17}$ Thus, whereas the realized volatilities are

\footnotetext{
15 The time series of realized volatilities in this and all of the subsequent HAR-RV regressions are implicitly assumed to be stationary. Formal tests for a unit root in $R V_{t,+1}$ easily reject the null hypothesis of non-stationarity for each of the three markets. Also, the standard log-periodogram estimates of the degree of fractional integration in $R V_{t,+1}$ equal $0.347,0.383$, and 0.437 , respectively, with a theoretical asymptotic standard error of 0.087 .

16 Related mixed data sampling, or MIDAS in the terminology of Ghysels, Santa-Clara and Valkanov (2004), regressions have recently been estimated by Ghysels, Santa-Clara and Valkanov (2005).

17 Note, that nothing prevents the forecasts of the realized volatilities from the HAR-RV-J model with $\beta_{\mathrm{J}}<0$ from becoming negative. We did not find this to be a problem for any of our in-sample model estimates, however. A more complicated multiplicative error structure, along the lines of Engle (2002) and Engle and Gallo (2005), could be employed to ensure positivity
} 
generally highly persistent, the impact of the lagged realized volatility is significantly reduced by the jump component. For instance, for the daily DM/\$ realized volatility a unit increase in the daily realized volatility implies an average increase in the volatility on the following day of $0.430+0.196 / 5+0.244 / 22=0.480$ for days where $J_{t}=0$, whereas for days in which part of the realized volatility comes from the jump component the increase in the volatility on the following day is reduced by -0.486 times the jump component. In other words, if the realized volatility is entirely attributable to jumps, it carries no predictive power for the following day's realized volatility. Similarly for the other two markets: the combined impact of a jump for forecasting the next day's realized volatility equals $0.341+0.485 / 5+0.165 / 22-0.472=-0.027$ and $0.074+0.317 / 5+0.358 / 22-$ $0.152=-0.002$, respectively.

Comparing the $R^{2}$ 's of the HAR-RV-J models to the $R^{2}$ 's of the "standard" HAR model reported in the last row in which the jump component is absent and the realized volatilities on the right-hand-side but not the left-hand-side of equation (11) are replaced by the corresponding lagged squared daily, weekly, and monthly returns clearly highlights the added value of the high-frequency data. Although the coefficient estimates of the $\beta_{D}, \beta_{W}$, and $\beta_{M}$ coefficients in the "standard" HAR models (available upon request) generally align fairly closely with those of the HAR-RV-J models reported in the tables, the explained variation is systematically lower. ${ }^{18}$ Importantly, the gains afforded by the use of the high-frequency based realized volatilities are not restricted to the daily and weekly horizons. In fact, the longer-run monthly forecasts result in the largest relative increases in the $R^{2}$, s, with those for the S\&P500 and T-Bonds tripling for the HAR-RV-J models relative to those from the HAR models based on the coarser daily, weekly, and monthly squared returns. These large gains in forecast accuracy through the use of realized volatilities are, of course, entirely consistent with the earlier empirical evidence in ABDL (2003), Bollerslev and Wright (2001) and Martens (2002), among others, and further corroborated by the analytical results of Andersen, Bollerslev and Meddahi (2004).

\section{B. Non-Linear HAR-RV-J Models}

Practical use of volatility models and forecasts often involves standard deviations as opposed to variances. The second set of columns in Tables 2A-C thus reports the parameter estimates and $R^{2}$ 's of the corresponding HAR-RV-J model cast in standard deviation form,

of the conditional expectations.

18 Note that although the relative magnitudes of the $R^{2}$, s for a given volatility series are directly comparable across the two models, as discussed in Andersen, Bollerslev and Meddahi (2005), the measurement errors in the left-hand-side realized volatility invariably result in a systematic downward bias in the reported $R^{2}$, s vis-a-vis the inherent predictability in the true latent quadratic variation process. 


$$
\left(R V_{t, t+h}\right)^{1 / 2}=\beta_{0}+\beta_{D} R V_{t}^{1 / 2}+\beta_{W}\left(R V_{t-5, t}\right)^{1 / 2}+\beta_{M}\left(R V_{t-22, t}\right)^{1 / 2}+\beta_{J} J_{t}^{1 / 2}+\epsilon_{t, t+h}
$$

The qualitative features and ordering of the different parameter estimates are generally the same as for the variance formulation in equation (11). In particular, the estimates for $\beta_{J}$ are systematically negative. Similarly, the $R^{2}$ 's indicate quite dramatic gains for the high-frequency based HAR-RV-J model relative to the standard HAR model. The more robust volatility measurements provided by the standard deviations also result in higher $R^{2}$ 's than for the variance-based models reported in the first three columns. ${ }^{19}$

As noted in Table 1 above, the logarithmic daily realized volatilities are approximately unconditionally normally distributed for each of the three markets. This empirical regularity motivated ABDL (2003) to model the logarithmic realized volatilities, in turn allowing for the use of standard normal distribution theory and related mixture models. ${ }^{20}$ Guided by this same idea, we report in the last three columns of Tables $2 \mathrm{~A}-\mathrm{C}$ the estimates of the logarithmic HAR-RV-J model,

$$
\begin{aligned}
\log \left(R V_{t, t+h}\right)=\beta_{0}+\beta_{D} \log \left(R V_{t}\right)+\beta_{W} \log \left(R V_{t, t-5}\right)+ & \beta_{M} \log \left(R V_{t,--22}\right) \\
& +\beta_{J} \log \left(J_{t}+1\right)+\epsilon_{t, t+h} .
\end{aligned}
$$

The estimates are again directly in line with those of the HAR-RV-J models for $R V_{t, t+h}$ and $\left(R V_{t, t+h}\right)^{1 / 2}$ discussed earlier. In particular, the $\beta_{D}$ coefficients are generally the largest in the daily models, the $\beta_{W}$ 's are the most important in the weekly models, and the $\beta_{M}$ 's in the monthly models. At the same time, the negative estimates of the $\beta_{J}$ coefficients temper the persistency in the forecasts, suggesting that jumps in the price processes tend to be associated with short-lived bursts in volatility.

\section{Shrinkage Estimation and Microstructure Noise Correction}

The empirical results discussed thus far rely on the simple non-parametric jump estimates defined by the difference between the realized volatility and the bi-power variation. As discussed in Section II, the theoretical justification for those measurements is based on the notion of increasingly finer sampled returns, or

19 The $R^{2}=0.431$ for the daily HAR-RV-J model for the DM/\$ realized volatility series in the fourth column in Table $2 \mathrm{~A}$ also exceeds the comparable in-sample one-day-ahead $R^{2}=0.355$ for the long-memory VAR model reported in ABDL (2003).

20 This same transformation has subsequently been used for other markets by Deo, Hurvich and Lu (2005), Koopman, Jungbacker and Hol (2005), Martens, van Dijk and Pooter (2004), and Oomen (2002) among others. Of course, the log-normal distribution isn't closed under temporal aggregation. Thus, if the daily logarithmic realized volatilities are normally distributed, the weekly and monthly volatilities can not also be log-normally distributed. However, as argued by Barndorff-Nielsen and Shephard (2002a) and Forsberg and Bollerslev (2002), the log-normal volatility distributions may be closely approximated by Inverse Gaussian distributions, which are formally closed under temporal aggregation. 
$\Delta \rightarrow 0$. Of course, any practical implementation with a fixed sampling frequency, or $\Delta>0$, is invariably subject to measurement error. The non-negativity truncation in equation (8) alleviates part of this finite-sample problem by eliminating theoretically infesible negative estimates for the squared jumps. However, the resulting $J_{t}^{1 / 2}$ series depicted in Figures 1A-C arguably also exhibit an unreasonably large number of non-zero small positive values. It may be desirable to treat these small jumps as measurement errors, or part of the continuous sample path variation process, associating only large values of $R V_{t}(\Delta)-B V_{t}(\Delta)$ with the jump component. The next sub-section provides a theoretical framework for doing so.

\section{A. Asymptotic Distribution Theory}

The distributional results developed in Barndorff-Nielsen and Shephard (2004a, 2005) and extended in Barndorff-Nielsen, Graversen, Jacod, Podolskij and Shephard (2005) imply that, under sufficient regularity, frictionless market conditions and in the absence of jumps in the price path,

$$
\Delta^{-1 / 2} \frac{R V_{t+1}(\Delta)-B V_{t+1}(\Delta)}{\left[\left(\mu_{1}^{-4}+2 \mu_{1}^{-2}-5\right) \int_{t}^{t+1} \sigma^{4}(s) d s\right]^{1 / 2}} \Rightarrow N(0,1)
$$

for $\Delta \rightarrow 0$. Hence, an abnormally large value of this standardized difference between $R V_{t+1}(\Delta)$ and $B V_{t+1}(\Delta)$ is naturally interpreted as evidence in favor of a "significant" jump over the $[t, t+1]$ time interval. Of course, the integrated quarticity that appears in the denominator needs to be estimated in order to actually implement this statistic. In parallel to the arguments underlying the robust estimation of the integrated volatility by the realized bi-power variation, it is possible to show that even in the presence of jumps, the integrated quarticity may be consistently estimated by the normalized sum of the product of $n \geq 3$ adjacent absolute returns raised to the power of $4 / n$. In particular, on defining the standardized realized tri-power quarticity measure,

$$
T Q_{t+1}(\Delta) \equiv \Delta^{-1} \mu_{4 / 3}^{-3} \sum_{j=3}^{1 / \Delta}\left|r_{t+j \cdot \Delta, \Delta}\right|^{4 / 3}\left|r_{t+(j-1) \cdot \Delta, \Delta}\right|^{4 / 3}\left|r_{t+(j-2) \cdot \Delta, \Delta}\right|^{4 / 3}
$$

where $\mu_{4 / 3} \equiv 2^{2 / 3} \cdot \Gamma(7 / 6) \cdot \Gamma(1 / 2)^{-1}=E\left(|Z|^{4 / 3}\right)$. It follows that for $\Delta \rightarrow 0$,

$$
T Q_{t+1}(\Delta) \Rightarrow \int_{t}^{t+1} \sigma^{4}(s) d s
$$


Combining the results in equations (14)-(16), the "significant" jumps may therefore be identified by comparing realizations of the feasible test statistics, ${ }^{21}$

$$
W_{t+1}(\Delta) \equiv \Delta^{-1 / 2} \frac{R V_{t+1}(\Delta)-B V_{t+1}(\Delta)}{\left[\left(\mu_{1}^{-4}+2 \mu_{1}^{-2}-5\right) T Q_{t+1}(\Delta)\right]^{1 / 2}}
$$

to a standard normal distribution.

The extensive simulation-based evidence for specific parametric continuous time diffusions reported in Huang and Tauchen (2005) suggests that the $W_{t+l}(\Delta)$ statistic defined in (17) tends to over-reject the null hypothesis of no jumps for large critical values. At the same time, following the approach advocated by Barndorff-Nielsen and Shephard (2004b), different variance stabilizing transforms for the joint asymptotic distribution of the realized volatility and bi-power variation measures generally produce test statistics with improved finite-sample performance. In particular, on applying the delta-rule to the joint bivariate distribution, Huang and Tauchen (2005) find that the ratio-statistic,

$$
Z_{t+1}(\Delta) \equiv \Delta^{-1 / 2} \frac{\left[R V_{t+1}(\Delta)-B V_{t+1}(\Delta)\right] R V_{t+1}(\Delta)^{-1}}{\left[\left(\mu_{1}^{-4}+2 \mu_{1}^{-2}-5\right) \max \left\{1, T Q_{t+1}(\Delta) B V_{t+1}(\Delta)^{-2}\right\}\right]^{1 / 2}},
$$

where the max adjustment follows by a Jensen's inequality argument as in Barndorff-Nielsen and Shephard (2004b), is very closely approximated by a standard normal distribution throughout its entire support in samples of the size relevant here. ${ }^{22}$ Moreover, they find that the ratio-statistic in (18) also has reasonable

\footnotetext{
21 Similar results were obtained by using the robust realized quad-power quarticity measure advocated in BarndorffNielsen and Shephard (2004a, 2005),

$$
Q Q_{t+1}(\Delta) \equiv \Delta^{-1} \mu_{1}^{-4} \sum_{j=4}^{1 / \Delta}\left|r_{t+j \cdot \Delta, \Delta}\right|\left|r_{t+(j-1) \cdot \Delta, \Delta}\right|\left|r_{t+(j-2) \cdot \Delta, \Delta}\right|\left|r_{t+(j-3) \cdot \Delta, \Delta}\right|
$$
}

Note however, that the realized quarticity,

$$
R Q_{t+1}(\Delta) \equiv R P V_{t+1}(\Delta, 4) \equiv \Delta^{-1} \mu_{4}^{-1} \sum_{j=1}^{1 / \Delta} r_{t+j \cdot \Delta, \Delta}^{4}
$$

used in estimating the integrated quarticity by Barndorff-Nielsen and Shephard (2002a) and Andersen, Bollerslev and Meddahi (2005) is not consistent in the presence of jumps, which in turn would result in a complete loss of power for the corresponding test statistic obtained by replacing $T Q_{t+1}(\Delta)$ in equation (17) with $R Q_{t+1}(\Delta)$.

${ }^{22}$ In an earlier version of this paper, we relied on the log-based statistic,

$$
U_{t+1}(\Delta) \equiv \Delta^{-1 / 2} \frac{\log \left(R V_{t+1}(\Delta)\right)-\log \left(B V_{t+1}(\Delta)\right)}{\left[\left(\mu_{1}^{-4}+2 \mu_{1}^{-2}-5\right) T Q_{t+1}(\Delta) B V_{t+1}(\Delta)^{-2}\right]^{1 / 2}},
$$


power against several empirically realistic calibrated stochastic volatility jump diffusion models.

Hence we naturally identify the "significant" jumps by the realizations of $Z_{t+1}(\Delta)$ in excess of some critical value, say $\Phi_{\alpha}$,

$$
J_{t+1, \alpha}(\Delta) \equiv I\left[Z_{t+1}(\Delta)>\Phi_{\alpha}\right] \cdot\left[R V_{t+1}(\Delta)-B V_{t+1}(\Delta)\right]
$$

where $I[\cdot]$ denotes the indicator function. ${ }^{23}$ To ensure that the estimated continuous sample path component variation and jump variation sum to the total realized variation, we estimate the former component as the residual,

$$
C_{t+1, \alpha}(\Delta) \equiv I\left[Z_{t+1}(\Delta) \leq \Phi_{\alpha}\right] \cdot R V_{t+1}(\Delta)+I\left[Z_{t+1}(\Delta)>\Phi_{\alpha}\right] \cdot B V_{t+1}(\Delta) .
$$

Note that for $\Phi_{\alpha}>0$, the definitions in equations (19) and (20) automatically guarantee that both $J_{t+1, \alpha}(\Delta)$ and $C_{t+1, \alpha}(\Delta)$ are positive. ${ }^{24}$ Of course, the non-negativity truncation imposed in equation (8) underlying the empirical jump measurements employed in the preceding two sections corresponds directly to $\alpha=0.5$, or $J_{t, 0.5}$.

\section{B. Market Microstructure Noise}

As already discussed in Section III.A, a host of practical market microstrucure frictions, including the use of discrete price grid points and bid-ask spreads, invariably renders fictitious the assumption of a continuously observed logarithmic price process following a semimartigale. Hence, following Aït-Sahalia, Mykland and Zhang (2005), Bandi and Russell (2004b), and Zhang, Mykland and Aït-Sahalia (2005), among others, assume that the observed price process is "contaminated" by a market microstructure noise component, say $p(t)=p^{*}(t)+v(t)$, where $p^{*}(t)$ refers to the true (latent) semimartingale logarithmic price process that would obtain in the absence of any frictions, while $v(t)$ denotes an i.i.d. white noise component. ${ }^{25}$ The discretely

which produced qualitatively very similar results.

23 As noted in personal communication with Neil Shephard, this may alternatively be interpreted as a shrinkage estimator for the jump component.

24 It is possible that, by specifying $\alpha(\Delta) \rightarrow 1$ as an explicit function of $\Delta \rightarrow 0$, this approach may formally be shown to result in period-by-period consistent (as $\Delta \rightarrow 0$ ) estimates of the jump component. Of course, data limitations restrict the sampling frequency $(\Delta>0)$, rendering such a result of limited practical use.

25 More complicated non-i.i.d. market microstructure noise components have been analyzed in the realized volatility setting by Bandi and Russell (2004a) and Hansen and Lunde (2006), among others. 
sampled $\Delta$-period observed returns,

$$
r_{t, \Delta} \equiv p^{*}(t)-p^{*}(t-\Delta)+v(t)-v(t-\Delta) \equiv r_{t, \Delta}^{*}+\eta_{t, \Delta}
$$

then equal the true (latent) returns plus the first-order moving average process, $\eta_{t, \Delta}$. Assuming that the variance of $v(t)$ does not depend upon $\Delta$, the noise term will eventually (for $\Delta \rightarrow 0$ ) dominate the contribution to the overall realized variation in (3) coming from the squared true (latent) high-frequency returns, formally rendering $R V_{t+1}(\Delta)$ inconsistent as a measure of the quadratic variation of $p^{*}(t)$. In practice, the impact of the market microstructure noise is most easily controlled through the choice of $\Delta$. Our choice of a five-minute sampling frequency for the very active markets analyzed here is motivated by this bias-variance tradeoff as the bias in the realized variation measure in equation (3) appears to largely vanish at this frequency.

By analogous arguments, the noise term will generally result in an upward bias in the new bi-power variation measure in equation (5) for $\Delta$ "too small," as $E\left(\left|r_{t, \Delta}^{*}\right|\right)<E\left(\left|r_{t, \Delta}^{*}+\eta_{t, \Delta}\right|\right)$. The first-order serial correlation in $\eta_{t, \Delta}$ further implies that any two adjacent observed returns, say $r_{t+j \cdot \Delta, \Delta}$ and $r_{t+(j-1) \cdot \Delta, \Delta}$, will be serially correlated. In comparison to the realized variation measure based on the sum of the squared highfrequency returns, this spuriously induced first-order serial correlation will therefore result in an additional source of bias in the $B V_{t+1}(\Delta)$ measure. Of course, similar arguments apply to the tri-power quarticity measure in equation (15). As discussed at length in Huang and Tauchen (2005), this in turn implies that in the presence of market microstructure noise, the jump test statistics discussed in the previous section will generally be biased against finding jumps. In particular, it is possible to show that in the absence of jumps, $\lim _{\Delta \rightarrow \infty}\left[R V_{t+1}(\Delta)-B V_{t+1}(\Delta)\right]=\kappa<0$, so that the $W_{t+1}(\Delta)$ test statistic defined in (17) will be negatively biased. Although comparable analytical results are not available for the ratio-statistic in equation (18), the numerical calculations and extensive simulation evidence reported in Huang and Tauchen (2005) confirm that for small values of $\Delta$, the test tends to be under-sized, and this tendency to under-reject further deteriorates with the magnitude of the variance of the $v(t)$ noise component.

The spurious serial correlation in the observed returns defined in equation (21) is, however, readily broken through the use of staggered, or skip-one, returns. Specifically, replacing the sum of the absolute adjacent returns in equation (5) with the corresponding staggered absolute returns, a modified realized bipower variation measure may be defined by 


$$
B V_{1, t+1}(\Delta) \equiv \mu_{1}^{-2}(1-2 \Delta)^{-1} \sum_{j=3}^{1 / \Delta}\left|r_{t+j \cdot \Delta, \Delta}\right|\left|r_{t+(j-2) \cdot \Delta, \Delta}\right|
$$

where the normalization factor in front of the sum reflects the loss of two observations due to the staggering. Of course, higher order serial dependence could be broken in an analogous fashion by further increasing the lag length. Similarly, the integrated quarticity may alternatively be estimated by the staggered realized tri-power quarticity,

$$
T Q_{1, t+1}(\Delta) \equiv \Delta^{-1} \mu_{4 / 3}^{-3}(1-4 \Delta)^{-1} \sum_{j=5}^{1 / \Delta}\left|r_{t+j \cdot \Delta, \Delta}\right|^{4 / 3}\left|r_{t+(j-2) \cdot \Delta, \Delta}\right|^{4 / 3}\left|r_{t+(j-4) \cdot \Delta, \Delta}\right|^{4 / 3}
$$

Importantly, as shown by Barndorff-Nielsen and Shephard (2004a), in the absence of the noise component, these staggered realized variation measures remain consistent for the corresponding integrated variation measures. Consequently, the asymptotic distribution of the test statistic obtained by replacing $B V_{t+1}(\Delta)$ and $T Q_{t+1}(\Delta)$ in equation (18) with their staggered counterparts, $B V_{1, t+1}(\Delta)$ and $T Q_{1, t+1}(\Delta)$, respectively, say $Z_{1, t+1}(\Delta)$, will also be asymptotically (for $\Delta \rightarrow 0$ ) standard normally distributed. However, following the discussion above, the staggering should help alleviate the confounding influences of the market microstructure noise, resulting in empirically more accurate finite sample approximations. This conjecture is indeed confirmed by the comprehensive simulation results reported in Huang and Tauchen (2005), which show that the ratiostatistic calculated with the staggered realized bi-power and tri-power variation measures performs admirably for a wide range of market microstructure contaminants. component. ${ }^{26}$

Hence, in the empirical results reported below we rely on the $J_{t, d}(\Delta)$ and $C_{t, d}(\Delta)$ measures previously defined in equations (19) and (20) calculated on the basis of the staggered $Z_{1, t}(\Delta)$ statistic. To facilitate the notation, we will again omit the explicit reference to the sampling frequency, $\Delta$, simply referring to the jump and continuous sample path variability measures calculated from the five-minute returns as $J_{t, \alpha}$ and $C_{t, \alpha}$, respectively. Subsequently we shall summarize various features of these jump measurements for values of $\alpha$ ranging from 0.5 to 0.9999 , or $\Phi_{\alpha}$ ranging from 0.0 to 3.719 .

\section{Jumps Measurements and Macroeconomic News}

Before summarizing the full sample time series evidence, it is instructive to look at a few specific days to illustrate the working of the jump statistic. To this end, Figure 2 displays the five-minute increments in the

\footnotetext{
${ }^{26}$ Quoting from the conclusion of Huang and Tauchen (2005): "The Monte Carlo evidence suggests that, under the arguable realistic scenarios considered here, the recently developed tests for jumps perform impressively and are not easily fooled."
} 
logarithmic prices for a highly significant jump day and a day with a large continuous price move for each of the three markets. For ease of comparison, the logarithmic price has been normalized to zero at the beginning of each day, so that a unit increment corresponds to a one-percent return in all of the graphs.

The first panel shows the movements in the DM/\$ exchange rate on December 10, 1987. The $Z_{1, t}$ statistics for this day equals 10.315 , thus indicating a highly significant jump. The timing of the jump, as evidenced by the apparent discontinuity at 13:30 GMT, corresponds exactly to the 8:30 EST release of the U.S. trade deficit for the month of October. ${ }^{27}$ Quoting from the Wall Street Journal: “The trade gap swelled to a record $\$ 17.63$ billion in October, sending the dollar and bonds plunging." The second panel in the first row depicts a similar large daily decline in the value of the dollar on September 17, 1992. In fact, this is the day in the entire sample with the highest value of $B V_{1, t}=4.037$. At the same time, the $Z_{1, t}$ statistic for this day equals -0.326 , and thus in spite of the overall large daily move, does not signify any jump(s). This particular day succeeds the day following the temporary withdrawal of the British Pound from the European Monetary System, and it has previously been highlighted in the study by Barndorff-Nielsen and Shephard (2005). Again, quoting from the Wall Street Journal: "The dollar and the pound each sank more than $2 \%$ against the mark as nervousness persisted in the currency market." Of course, without the benefit of the intraday high-frequency data, the day-to-day price moves in the first two panels would look almost identical.

Turning to the second row in the figure, the first panel shows the five-minute movements in the S\&P500 on June 30, 1999. As suggested by visual inspection of the plot, the $Z_{1, t}=7.659$ statistic is again highly significant. Moreover, the apparent timing of the jump at 13:15 CST, or 14:15 EST, corresponds exactly to the time of the $1 / 4 \%$ increase in the FED funds rate on that day. That rate hike was accompanied by a statement by the FED that it "might not raise rates again in the near term due to conflicting forces in the economy," which apparently was viewed as a positive sign by the market. In contrast, on July 24, 2002, as depicted in the panel on the right, $Z_{1, t}=-0.704$, while $B V_{l, t}$ achieves its maximum value of 29.247. The abnormally large daily return of 7.157 is also the largest over the whole sample. Yet, this "rough" daily move is made up of the sum of many "smooth" intraday price moves, with no apparent jump(s) in the process. Interestingly, the NYSE also saw a record trading volume of 2.77 billion shares on that day.

The last row in the figure refers to the T-Bond market. The apparent timing of the highly significant jump, $Z_{1, t}=6.877$, on August 1, 1996, corresponds directly to the release of the National Association of

\footnotetext{
27 The systematic news announcement analysis in Andersen, Bollerslev, Diebold and Vega (2003, 2005) also points to the U.S. trade balance as one of the most important regularly scheduled macroeconomic news releases for the foreign exchange market.
} 
Purchasing Manager's (NAPM) index at 9:00 CST, or 10:00 EST. ${ }^{28}$ In contrast, the second T-Bond panel for December 7, 2002 again depicts a large daily, but generally "smooth" intraday, price move. Interestingly, most of the movements occurred in the morning following news of higher than expected joblessness. While this did not result in an immediate jump in the T-Bond price, it reassured most economist's that the FED would cut its rate at the next Board meeting the following business day, which in fact it did. According to Wall Street Journal: "Economists said the jobs report removed any lingering doubts that the Federal Reserve will reduce interest rates for the $11^{\text {th }}$ time in the past 12 months when it meets tomorrow."

The direct association of the highly significant jump days in Figure 2 with readily identifiable macroeconomic news affirms earlier case studies for the $\mathrm{DM} / \$$ foreign exchange market in Barndorff-Nielsen and Shephard (2005) and is directly in line with the aforementioned evidence in Andersen, Bollerslev, Diebold and Vega $(2003,2005)$ among others, documenting significant intra-daily price moves in response to a host of macroeconomic news announcements. Similarly, Johannes (2004) readily associates the majority of the estimated jumps in a parametric jump-diffusion model for daily interest rates with specific macroeconomic news events. At the same time, informal inspection suggests that not all of the jump days identified by large values of the non-parametric high-frequency $Z_{1, t}$ statistic are as easily linked to specific "news" arrivals. Indeed, it would be interesting, but beyond the scope of the present paper, to attempt a more systematic characterization of the types of events that cause the different markets to jump. Instead, we turn to a discussion of various summary statistics related to the time series of significant jumps employed in our subsequent volatility forecasting models.

\section{Jump Dynamics}

To begin, the first row in Tables 3A-C reports the proportion of days with significant jumps for each of the three markets based on the $Z_{1, t}$ statistic as a function of the significance level, $\alpha$. Although the use of $\alpha$ 's in excess of 0.5 has the intended effect of reducing the number of days with jumps, the procedure still identifies many more significant jumps than would be expected if the underlying price process was continuous. Comparing the jump intensities across the three markets, the foreign exchange and the T-Bond markets generally exhibit the highest proportion of jumps, whereas the stock market has the lowest. ${ }^{29}$ For instance,

\footnotetext{
28 The results in Andersen, Bollerslev, Diebold and Vega (2005) again indicate that, for the T-Bond market, news about the NAPM index results in the overall highest five-minute return regression $R^{2}$ among all of the regularly scheduled macroeconomic announcements.

29 This ordering among the three markets is again consistent with the evidence in Andersen, Bollerslev, Diebold and Vega (2005), showing that equity markets generally respond the least to macroeconomic news announcements.
} 
employing a cutoff of $\alpha=0.999$, or $\Phi_{\alpha}=3.090$, results in 417,244 , and 424 significant jumps for each of the three markets respectively, all of which far exceed the expected three jumps for a continuous price process (0.001 times 3,045 and 3,213, respectively). Indeed, all of the daily jump proportions are much higher than the jump intensities estimated with specific parametric jump diffusion models applied to daily or coarser frequency returns, which typically suggest only a few jumps a year; see, e.g., the estimates for the S\&P500 in Andersen, Benzoni and Lund (2002). Intuitively, just as the stock market crash of 1987 and the corresponding large negative daily return on October 17 is not visible in the time series of annual equity returns, many of the jumps identified by the high-frequency based realized variation measures employed here will invariably be hidden in the coarser daily or lower frequency returns.

Turning to the second and third rows in the table, it is noteworthy that although the proportion of jumps depend importantly on the particular choice of $\alpha$, the sample means and standard deviations of the resulting jump time series are not nearly as sensitive to the significance level. This observation is further corroborated by the time series plots for each of the three markets in the third and fourth panels in Figures 1A$1 \mathrm{C}$, which show the $Z_{1, t}$ statistics and a horizontal line at 3.090, along with the resulting significant jumps, or $J_{t, 0.999}^{1 / 2}$. It is evident that the test statistic generally picks out the largest values of $J_{t}^{1 / 2}$ as being significant, so that the sample means and standard deviations of the time series depicted in the second and the fourth panels are all fairly close.

The Ljung-Box statistics for up to tenth order serial correlation in the $J_{t, \alpha}$ series for the S\&P500 reported in the fourth row in Table 3B are all highly significant, regardless of the choice of $\alpha$. This contrasts with most of the parametric jump-diffusion model estimates reported in the recent literature, which as previously noted suggest very little, or no, predictable variation in the jump process. Still, it is noteworthy that the values of the Ljung-Box statistics for the significant S\&P500 jumps are all much less than the corresponding statistics for the realized variation series reported in Table 1B. The corresponding Ljung-Box tests for the DM/\$ and T-Bond jump series are not nearly as large, and generally insignificant for the jumps defined by $\alpha$ 's in excess of 0.990 .

These findings are further corroborated by Christoffersen's (1998) Likelihood Ratio test for the null of i.i.d. jumps against a first-order Markov alternative reported in the fifth row. Under the null of no dependence this test statistic should be asymptotically chi-square distributed with one degree of freedom. None of the test statistics for $\alpha$ equal to 0.999 or 0.9999 for the $\mathrm{DM} / \$$ and T-Bond markets exceed the corresponding 95 -percent critical value of 3.84 , while the tests for the S\&P500 are highly significant.

Interestingly, when looking beyond the own linear dependence and the Ljung-Box test for the $J_{t, \alpha}$ series, a somewhat different picture emerges. In particular, decomposing the $J_{t, \alpha}$ series into the times between 
jumps and the sizes of the corresponding jumps, there appears to be strong evidence for clustering in the occurrences of the significant jumps for both the S\&P500 and T-Bond markets, as evidenced by the Ljung-Box test for up to tenth order serial correlation in the durations between the jumps, denoted by $\mathrm{LB}_{10}, D_{t, \alpha}$ in Table 3 . Similarly, the Ljung-Box tests for serial correlation in the time series of only the significant jumps, denoted by $\mathrm{LB}_{10}, J_{t, \alpha}{ }^{+}$in Table 3, strongly suggest that large (small) jumps tend to cluster together in time with other large (small) jumps for both the DM/ $\$$ and S\&P500 markets. In contrast, for the T-Bond market and $\alpha=0.999$, only the durations but not the sizes of the jumps appear to cluster in time.

The more complex dynamic dependence in the significant jump time series is further illustrated in Figure 3, which plots the smoothed jump intensities and jump sizes for each of the three markets. The graphs are constructed by exponentially smoothing (with a smoothing parameter of 0.94 ) the average monthly jump intensities and sizes of the significant jumps based on $\alpha=0.999$. The jump sizes are again expressed in standard deviation form, or $J_{t, 0.999}^{1 / 2}$. From the very first panel the DM/ jump intensities are approximately constant throughout the sample. Similarly, the smoothed jump sizes for the T-Bond market depicted in the last panel vary very little over the sample period. In contrast, all of the other four panels suggest the existence of potentially important temporal dependence in the jump arrival processes and jump sizes. ${ }^{30}$ Of course, exponential smoothing automatically induces some serial correlation, so that the appearance of dependence gleaned from the figure should be carefully interpreted. Note also that the common scale enforced on the three jump size panels tends to hide the subtle, but systematic, decline in the sizes of the jumps for the DM/\$ market over the sample period, as evidenced by the highly significant LB10, $J_{t, \alpha}{ }^{+}$in Table 3 ; see also the plot for the raw jump series in Figure 1A.

Instead, we next turn to a simple extension of the HAR-RV-J volatility forecasting model introduced in Section IV, in which we incorporate the time series of significant jumps as additional explanatory variables in a straightforward linear fashion.

\section{Accounting for Jumps in Realized Volatility Modeling and Forecasting, Revisited}

The regression estimates of the HAR-RV-J model reported in Section IV show that inclusion of the simple consistent daily jump measure corresponding to $\alpha=0.5$ as an additional explanatory variable over-and-

\footnotetext{
30 It would be interesting, but beyond the scope of the present paper, to further explore the formulation of parametric jump-diffusion models best designed to capture such non-linear dependence. For instance, following Bates (2000), Pan (2002) and Eraker (2004), the jump intensity could be specified as a function of the instantaneous diffusion volatility. In the notation of equation (1), $\lambda(t)=\lambda_{0}+\lambda_{l} \sigma(t)$. Similarly, the size of the jumps could be allowed to depend on the volatility and/or lagged past jump sizes, as in, e.g., $\kappa^{2}(t)=\kappa_{0}+\kappa_{1} \sigma(t)+\kappa_{2} \kappa^{2}\left(t_{-1}\right)$. The recent discrete-time parametric model estimates reported in Chan and Maheu (2002) and McCurdy and Maheu (2004) also point to the existence of time-varying jump intensities in U.S. equity index returns.
} 
above the daily realized volatilities results in highly significant and negative estimates of the jump coefficient. These results are, of course, entirely consistent with the summary statistics for the jump measurements discussed above, which indicate markedly less own (linear) serial correlation in the significant jump series in comparison to the realized volatility series. Building on these results, the present section extends the HARRV-J model by explicitly decomposing the realized volatilities that appear as explanatory variables on the right-hand-side into the continuous sample path variability and the jump variation utilizing the separate nonparametric measurements based on the $Z_{1, t}$ statistic along with equations (19) and (20), respectively. In so doing, we rely exclusively on $\alpha=0.999$, and the jump series depicted in the bottom panels of Figures $1 \mathrm{~A}-\mathrm{C} .{ }^{31}$ To facilitate the exposition, we omit the 0.999 subscript on the $J_{t, 0.999}$ and $C_{t, 0.999}$ series in what follows.

\section{A. The HAR-RV-CJ Model}

Defining the normalized multi-period jump and continuous sample path variability measures,

$$
J_{t, t+h}=h^{-1}\left[J_{t+1}+J_{t+2}+\ldots+J_{t+h}\right]
$$

and,

$$
C_{t, t+h}=h^{-1}\left[C_{t+1}+C_{t+2}+\ldots+C_{t+h}\right]
$$

respectively, the new HAR-RV-CJ model may be expressed as

$$
\begin{aligned}
R V_{t, t+h}=\beta_{0}+ & \beta_{C D} C_{t}+\beta_{C W} C_{t-5, t}+\beta_{C M} C_{t-22, t}+ \\
& +\beta_{J D} J_{t}+\beta_{J W} J_{t-5, t}+\beta_{J M} J_{t-22, t}+\varepsilon_{t, t+h} .
\end{aligned}
$$

The model obviously nests the HAR-RV-J model in (11) for $\beta_{D}=\beta_{C D}+\beta_{J D}, \beta_{W}=\beta_{C W}+\beta_{J W}, \beta_{M}=\beta_{C M}+\beta_{J M}$, and $\beta_{J}$ $=\beta_{J D}$, but in general it allows for a more flexible dynamic lag structure. ${ }^{32}$

Turning to the empirical estimates in the first three columns in Tables 4A-C, most of the jump coefficient estimates are insignificant. In other words, the predictability in the HAR-RV realized volatility regressions is almost exclusively due to the continuous sample path components. For the $\mathrm{DM} / \$$ and the S\&P500 the HAR-RV-CJ models typically result in relatively modest increases in the $R^{2}$ of less than 0.01 in

\footnotetext{
31 By "optimally" choosing $\alpha$, it may be possible to further improve upon the empirical results reported below. However, for simplicity and to guard against obvious data snooping biases, we simply restrict $\alpha=0.999$.

32 For the two models to be nested the (implicit) choice of $\alpha$ employed in the measurements of $J_{t, t+h}$ and $C_{t, t+h}$ should, of course, be the same across models.
} 
absolute value compared to the HAR-RV-J models in Tables 2A-B, whereas for the T-Bond market the improvements are closer to 0.02 , or about $4-5$ percent in a relative sense. The tests for first, sixth, and twentythird order serial correlation in the residuals from the estimated daily $(h=1)$, weekly $(h=5)$, and monthly $(h=22)$ regressions also indicate that the HAR-RV-CJ models have eliminated most of the strong serial correlation in the $R V_{t, t+h}$ series. ${ }^{33}$ Still, some statistically significant autocorrelations remain at higher lags for some of the models, suggesting that further refinements might be possible.

These same qualitative results carry over to the non-linear HAR-RV-CJ models cast in standard deviation and logarithmic form; i.e.,

$$
\begin{aligned}
\left(R V_{t, t+h}\right)^{1 / 2}= & \beta_{0}+\beta_{C D} C_{t}^{1 / 2}+\beta_{C W}\left(C_{t-5, t}\right)^{1 / 2}+\beta_{C M}\left(C_{t-22, t}\right)^{1 / 2} \\
& +\beta_{J D} J_{t}^{1 / 2}+\beta_{J W}\left(J_{t-5, t}\right)^{1 / 2}+\beta_{J M}\left(J_{t-22, t}\right)^{1 / 2}+\varepsilon_{t, t+h},
\end{aligned}
$$

and,

$$
\begin{aligned}
\log \left(R V_{t, t+h}\right)= & \beta_{0}+\beta_{C D} \log \left(C_{t}\right)+\beta_{C W} \log \left(C_{t-5, t}\right)+\beta_{C M} \log \left(C_{t-22, t}\right) \\
& +\beta_{J D} \log \left(J_{t}+1\right)+\beta_{J W} \log \left(J_{t-5, t}+1\right)+\beta_{J M} \log \left(C_{t-22, t}+1\right)+\varepsilon_{t, t+h},
\end{aligned}
$$

respectively. The jump coefficient estimates, reported in the last six columns in Tables 4A-C, are again insignificant for most of the markets and forecast horizons. In contrast, the estimates of $\beta_{C D}, \beta_{C W}$, and $\beta_{C M}$, which quantify the impact of the continuous sample path variability on the total future variation, are all generally highly significant.

To further illustrate the predictability afforded by the HAR-RV-CJ model, Figures 4A-C plot the daily, weekly, and monthly realized volatilities (again in standard deviation form) together with the corresponding forecasts from the model in equation (27). The close coherence between the different pairs of realizations and forecasts is immediately evident across all of the markets and forecast horizons. Visual inspection of the graphs also shows that the volatility in the U.S. T-Bond market is the least predictable, followed by the DM/\$, and then the S\&P500. Nonetheless, the forecasts of the T-Bond volatilities still track the overall patterns fairly well, especially for the longer weekly and monthly horizons.

All told, these results underscore the potential benefit from a volatility forecasting perspective of separately measuring the individual components of the realized volatility. It is possible that even further

\footnotetext{
33 The lag one, six, and twenty-three autocorrelations of the residuals from the three DM/\$ HAR-RV-CJ models are $0.014,-0.026$, and 0.003 , respectively. For the S\&P500, the same residual autocorrelations are $-0.011,0.007$, and -0.081 , while for $\mathrm{T}$-Bonds the autocorrelations are $0.003,-0.006$, and -0.060 , respectively.
} 
improvements may be obtained by a more structured approach in which the jump component, $J_{t}$, and the continuous sample path component, $C_{t}$, are each modeled separately. These individual models for $J_{t}$ and $C_{t}$ could then be used in the construction of separate out-of-sample forecasts for each of the components, as well as combined forecasts of the total realized variation process, $R V_{t, t+h}=C_{t, t+h}+J_{t, t+h}$. We leave further work along these lines for future research.

\section{Concluding Remarks}

Building on recent theoretical results in Barndorff-Nielsen and Shephard (2004a, 2005) for bi-power variation measures, we provide a simple and easy-to-implement practical framework for measuring "significant" jumps in financial asset prices. Applying the theory to more than a decade of high-frequency prices from the foreign exchange, equity, and fixed income markets, we find that the procedure works well empirically. Our non-parametric measurements suggest that jumps dynamics are much less persistent (and predictable) than continuous sample path dynamics. In addition, the high-frequency data underlying our estimates allow us to identify many more jumps than do the parametric models based on daily or courser frequency data hitherto reported in the literature. It also appears that many of the most significant jumps are readily associated with specific macroeconomic news announcements. Finally, when separately including the continuous sample path and jump variability measures in a simple linear volatility forecasting model, we find that only the continuous part has predictive power, in turn resulting in significant gains relative to the simple realized volatility forecasting models advocated in some of the recent literature.

The ideas and empirical results presented here are suggestive of several interesting extensions. First, it seems natural that jump risk may be priced differently from easier-to-hedge continuous price variability; see, e.g., Santa-Clara and Yan (2004). Hence, separately modeling and forecasting the continuous sample path, or integrated volatility, and jump components of the quadratic variation process, as discussed above, is likely to result in important improvements in derivatives and other pricing decisions.

Second, our choice of a five-minute sampling frequency and the new skip-one realized bi-power and tri-power variation measures to mitigate the market microstructure frictions in the high-frequency data were based on intuitive but informal considerations. It would be interesting to further investigate the "optimal" choice of sampling frequency, or the use of optimal sub-sampling schemes in the construction of the bi- and tripower variation measures. The related results for the realized variation measures in, e.g., Bandi and Russell (2004a,b), Hansen and Lunde (2006) and Zhang, Aït-Sahalia and Mykland (2005), should be helpful.

Third, if interest centers exclusively on volatility forecasting, the use of more traditional robust power variation measures defined by the sum of absolute high-frequency returns raised to powers less than two might 
afford additional gains over and above the improvements provided by the bi-power variation and significant jump measures used here; the recent empirical results in Forsberg and Ghysels (2004) are suggestive.

Fourth, casual empirical observation suggests that very large price moves, or jumps, often occur simultaneously across different markets. It would be interesting to extend the present analysis to a multivariate framework explicitly incorporating such commonalities through the use of quadratic covariation and appropriately defined co-power variation measures; the abstract theoretical results in Barndorff-Nielsen, Graversen, Jacod, Podolskij and Shephard (2005) are intriguing. In addition to allowing for more accurate statistical identification of the most important, or significant, jumps, this should also enhance our understanding of the underlying economic influences that "drive" financial markets and prices.

Last, and not at all least, additional exploration of variations on the shrinkage estimation undertaken here would be of great interest. We simply shrink raw jump estimates toward zero by setting all those less than some arbitrary threshold (motivated by classical asymptotic distribution theory) to zero. This "hard threshold" contrasts with the "soft thresholds" typical of Bayesian shrinkage, which would involve coaxing, but not forcing, of raw jump estimates toward zero. A thorough Bayesian analysis must, however, await future work. 


\section{References}

Aït-Sahalia, Y. (2002), “Telling from Discrete Data Whether the Underlying Continuous-Time Model is a Diffusion," Journal of Finance, 57, 2075-2121.

Aït-Sahalia, Y. (2004), "Disentangling Volatility from Jumps,” Journal of Financial Economics, 74, 487-528.

Aït-Sahalia, Y., P.A. Mykland and L. Zhang (2005), "How Often to Sample a Continuous-Time Process in the Presence of Market Microstructure Noise," Review of Financial Studies, 18, 351-416.

Andersen, T.G., L. Benzoni and J. Lund (2002), "Estimating Jump-Diffusions for Equity Returns," Journal of Finance, 57, 1239-1284.

Andersen, T.G. and T. Bollerslev (1997), "Heterogeneous Information Arrivals and Return Volatility Dynamics: Uncovering the Long-Run in High-Frequency Returns," Journal of Finance, 52, 975-1005.

Andersen, T.G. and T. Bollerslev (1998), "Answering the Skeptics: Yes, Standard Volatility Models Do Provide Accurate Forecasts,” International Economic Review, 39, 885-905.

Andersen, T.G., T. Bollerslev and F.X. Diebold (2005), "Parametric and Non-Parametric Volatility Measurement," in Handbook of Financial Econometrics (L.P Hansen and Y. Aït-Sahalia, eds.). Elsevier Science, New York, forthcoming.

Andersen, T.G., T. Bollerslev, F.X. Diebold and H. Ebens (2001), "The Distribution of Realized Stock Return Volatility,” Journal of Financial Economics, 61, 43-76.

Andersen, T.G., T. Bollerslev, F.X. Diebold and P. Labys (2000), “Great Realizations,” Risk, 13, 105-108.

Andersen, T.G., T. Bollerslev, F.X. Diebold and P. Labys (2001), “The Distribution of Realized Exchange Rate Volatility,” Journal of the American Statistical Association, 96, 42-55.

Andersen, T.G., T. Bollerslev, F.X. Diebold and P. Labys (2003), "Modeling and Forecasting Realized Volatility," Econometrica, 71, 579-625.

Andersen, T.G., T. Bollerslev, F.X. Diebold and C. Vega (2003), "Micro Effects of Macro Announcements: RealTime Price Discovery in Foreign Exchange,” American Economic Review, 93, 38-62.

Andersen, T.G., T. Bollerslev, F.X. Diebold and C. Vega (2005), "Real-Time Price Discovery in Stock, Bond and Foreign Exchange Markets," Manuscript, Northwestern University, Duke University, University of Pennsylvania, and University of Rochester.

Andersen, T.G., T. Bollerslev and N. Meddahi (2004), “Analytic Evaluation of Volatility Forecasts," International Economic Review, 45, 1079-1110.

Andersen, T.G., T. Bollerslev and N. Meddahi (2005), "Correcting the Errors: Volatility Forecast Evaluation using High-frequency Data and Realized Volatilities," Econometrica, 72, 279-296.

Andreou, E. and E. Ghysels (2002), "Rolling-Sample Volatility Estimators: Some New Theoretical, Simulation, and Empirical Results,” Journal of Business and Economic Statistics, 20, 363-376. 
Areal, N.M.P.C. and S.J. Taylor (2002), “The Realized Volatility of FTSE-100 Futures Prices,” Journal of Futures Markets, 22, 627-648.

Bai, X., J.R. Russell and G.C. Tiao (2004), "Effects of Non-Normality and Dependence on the Precision of Variance Estimates using High-Frequency Financial Data," Manuscript, University of Chicago.

Baillie, R.T., T. Bollerslev, and H.O. Mikkelsen (1996), "Fractionally Integrated Generalized Autoregressive Conditional Heteroskedasticity," Journal of Econometrics, 74, 3-30.

Ball, C.A. and W.N. Torous (1983), “A Simplified Jump Process for Common Stock Returns,” Journal of Financial and Quantitative Analysis, 18, 53-65.

Bandi, F.M. and J.R. Russell (2004a), “Microstructure Noise, Realized Volatility, and Optimal Sampling,” Manuscript, University of Chicago.

Bandi, F.M. and J.R. Russell (2004b), "Separating Microstructure Noise from Volatility” Manuscript, University of Chicago.

Barndorff-Nielsen, O.E., S.E. Graversen, J. Jacod, M. Podolskij and N. Shephard (2005), "A Central Limit Theorem for Realised Power and Bipower Variation of Continuous Semimartingales," in From Stochastic Analysis to Mathematical Finance, Festschrift for Albert Shiryaev (Y. Kabanov and R. Lipster, eds.). Springer Verlag.

Barndorff-Nielsen, O.E., S.E. Graversen and N. Shephard (2004), "Power Variation and Stochastic Volatility: A Review and Some New Results," Journal of Applied Probability, 41A, 133-143.

Barndorff-Nielsen, O.E., P.R. Hansen, A. Lunde and N. Shephard (2005), "Regular and Modified Kernel-Based Estimators of Integrated Variance: The Case with Independent Noise,” Manuscript, Stanford University.

Barndorff-Nielsen, O.E. and N. Shephard (2002a), "Econometric Analysis of Realised Volatility and its use in Estimating Stochastic Volatility Models," Journal of the Royal Statistical Society, 64, 253-280.

Barndorff-Nielsen, O.E. and N. Shephard (2002b), "Estimating Quadratic Variation Using Realized Variance," Journal of Applied Econometrics, 17, 457-478.

Barndorff-Nielsen, O.E. and N. Shephard (2003), "Realised Power Variation and Stochastic Volatility," Bernoulli, 9, 243-265.

Barndorff-Nielsen, O.E. and N. Shephard (2004a), "Power and Bipower Variation with Stochastic Volatility and Jumps," Journal of Financial Econometrics, 2, 1-37.

Barndorff-Nielsen, O.E. and N. Shephard (2004b), "How Accurate is the Asymptotic Approximation to the Distribution of Realised Volatility," in Identification and Inference for Econometric Models. A Festschrift in Honour of T.J. Rothenberg (D. Andrews, J. Powell, P.A. Ruud, and J. Stock, eds.). Cambridge, UK: Cambridge University Press.

Barndorff-Nielsen, O.E. and N. Shephard (2005), "Econometrics of Testing for Jumps in Financial Economics Using Bipower Variation," Journal of Financial Econometrics, forthcoming.

Basak, G., N.H. Chan, and W. Palma (2001), "The Approximation of Long-Memory Processes by an ARMA Model," Journal of Forecasting, 20, 367-389. 
Bates, D.S. (2000), "Post- 87 Crash fears in the S\&P500 Futures Option Market,” Journal of Econometrics, 94, 181238.

Beckers, S. (1981), “A Note on Estimating the Parameters of the Diffusion-Jump Model of Stock Returns,” Journal of Financial and Quantitative Analysis, 16, 127-140.

Bollen, B. and B. Inder (2002), "Estimating Daily Volatility in Financial Markets Utilizing Intraday Data," Journal of Empirical Finance, 9, 551-562.

Bollerslev, T. and J.H. Wright (2001), "Volatility Forecasting, High-Frequency Data, and Frequency Domain Inference," Review of Economics and Statistics, 83, 596-602.

Breidt, F.J., N. Crato and P. de Lima (1998), “The Detection and Estimation of Long-Memory in Stochastic Volatility," Journal of Econometrics, 83, 325-348.

Calvet, L. and A. Fisher (2001), “Forecasting Multifractal Volatility,” Journal of Econometrics, 105, 27-58.

Calvet, L. and A. Fisher (2002), "Multifractality in Asset Returns: Theory and Evidence," Review of Economics and Statistics, 84, 381-406.

Chan, W.H. and J.M. Maheu (2002), “Conditional Jump Dynamics in Stock Market Returns,” Journal of Business and Economic Statistics, 20, 377-389.

Chernov, M., A.R. Gallant, E. Ghysels, and G. Tauchen (2003), “Alternative Models for Stock Price Dynamics,” Journal of Econometrics, 116, 225-257.

Christoffersen, P. (1998), “Evaluating Interval Forecasts,” International Economic Review, 39, 841-862.

Comte, F. and E. Renault (1998), "Long Memory in Continuous Time Stochastic Volatility Models," Mathematical Finance, 8, 291-323.

Corsi, F. (2003), “A Simple Long Memory Model of Realized Volatility,” Manuscript, University of Southern Switzerland.

Corsi, F., Zumbach, U.A. Müller and M. Dacorogna (2001), "Consistent High-Precision Volatility from Highfrequency Data," Economic Notes, 30, 183-204.

Cox, D.R. (1991), “Long-Range Dependence, Non-Linearity and Time Irreversibility," Journal of Time Series Analysis, 12, 329-335.

Curci, G. and F. Corsi (2003), “A Discrete Sine Transform Approach for Realized Volatility Measurement,” Manuscript, University of Pisa.

Dacorogna, M.M., U.A. Müller, R.J. Nagler, R.B. Olsen and O.V. Pictet (1993), “A Geographical Model for the Daily and Weekly Seasonal Volatility in the Foreign Exchange Market," Journal of International Money and Finance, 12, 413-438.

Dacorogna, M.M., R. Gencay, U.A. Müller, O.V. Pictet and R.B. Olsen (2001). An Introduction to High-Frequency Finance. San Diego: Academic Press. 
Das, S.R. (2002), “The Surprise Element: Jumps in Interest Rates,” Journal of Econometrics, 106, 27-65.

Deo, R., C. Hurvich, and Y. Lu (2005), "Forecasting Realized Volatility Using a Long-Memory Stochastic Volatility Model: Estimation, Prediction and Seasonal Adjustment," Journal of Econometrics, forthcoming.

Ding, Z., C.W.J. Granger and R.F. Engle (1993), “A Long-Memory Property of Stock Market Returns and a New Model," Journal of Empirical Finance, 1, 83-106.

Drost, F.C., T.E. Nijman and B.J.M. Werker (1998), "Estimation and Testing in Models Containing Both Jumps and Conditional Heteroskedasticity," Journal of Business and Economic Statistics, 16, 237-243.

Engle, R.F. (2000), “The Econometrics of Ultra-High Frequency Data,” Econometrica, 68, 1-22.

Engle, R.F. (2002), “New Frontiers for ARCH Models,” Journal of Applied Econometrics, 17, 425-446.

Engle, R.F. and G.M. Gallo (2005), “A Multiple Indicators Model for Volatility Using Intra-Daily Data,” Journal of Econometrics, forthcoming.

Engle, R.F. and G.J. Lee (1999), “A Permanent and Transitory Component Model of Stock Return Volatility,” in Cointegration, Causality, and Forecasting: A Festschrift in Honor of Clive W.J. Granger (R.F. Engle and H. White, eds.). Oxford, UK: Oxford University Press.

Eraker, B. (2004), "Do Stock Prices and Volatility Jump? Reconciling Evidence from Spot and Option Prices," Journal of Finance, 59, 1367-1403.

Eraker, B., M.S. Johannes and N.G. Polson (2003), “The Impact of Jumps in Volatility,” Journal of Finance, 58, 1269-1300.

Forsberg, L. and T. Bollerslev (2002), "Bridging the Gap Between the Distribution of Realized (ECU) Volatility and ARCH Modeling (of the Euro): The GARCH-NIG Model," Journal of Applied Econometrics, 17, 535-548.

Forsberg, L. and E. Ghysels (2004), “Why Do Absolute Returns Predict Volatility So Well?,” Manuscript, University of North Carolina, Chapel Hill..

Gallant, A.R., C.T. Hsu and G. Tauchen (1999), "Using Daily Range Data to Calibrate Volatility Diffusions and Extract the Forward Integrated Variance," Review of Economics and Statistics, 81, 617-631.

Ghysels, E, P. Santa-Clara and R. Valkanov (2004), "The MIDAS Touch: Mixed Data Sampling Regressions," Manuscript, University of North Carolina and UCLA.

Ghysels, E, P. Santa-Clara and R. Valkanov (2005), "Predicting Volatility: How to Get the Most out of Returns Data Sampled at Different Frequencies," Journal of Econometrics, forthcoming.

Hansen, P.R. and A. Lunde (2006), "Realized Variance and Market Microstructure Noise," Journal of Business and Economic Statistics, forthcoming.

Hsu, N.J. and F.J. Breidt (2003), "Bayesian Analysis of Fractionally Integrated ARMA with Additive Noise," Journal of Forecasting, 22, 491-514. 
Huang, X. and G. Tauchen (2005), “The Relative Contribution of Jumps to Total Price Variance” Manuscript, Duke University.

Jarrow, R.A. and E. Rosenfeld (1984), “Jump Risk and the Intertemporal Capital Asset Pricing Model,” Journal of Business, 57, 337-351.

Johannes, M. (2004), “The Statistical and Economic Role of Jumps in Continuous-Time Interest Rate Models," Journal of Finance, 59, 227-260.

Johannes, M., R. Kumar and N.G. Polson (1999), “State Dependent Jump Models: How do US Equity Markets Jump?" Manuscript, University of Chicago.

Jorion, P. (1988), “On Jump Processes in the Foreign Exchange and Stock Markets,” Review of Financial Studies, 1, 427-445.

Khalaf, L., J.-D. Saphores and J.-F. Bilodeau (2003), "Simulation-Based Exact Jump Tests in Models with Conditional Heteroskedasticity," Journal of Economic Dynamics and Control, 28, 531-553.

Koopman, S.J., B. Jungbacker and E. Hol (2005), "Forecasting Daily Variability of the S\&P100 Stock Index Using Historical, Realised and Implied Volatility Measures," Journal of Empirical Finance, forthcoming.

Maheu, J.M. and T.H. McCurdy (2004), "News Arrival, Jump Dynamics and Volatility Components for Individual Stock Returns,” Journal of Finance, 59, 755-793.

Malliavin, P. and M.E. Mancino (2002), "Fourier Series Methods for Measurement of Multivariate Volatilities," Finance and Stochastics, 6, 49-61.

Man, K.S. (2003), "Long Memory Time Series and Short Term Forecasts," International Journal of Forecasting, 19, 477-491.

Mancini, C. (2003), "Statistics of a Poisson-Gaussian Process,” Manuscript, Universita di Firenze.

Mancini, C. (2004), "Estimation of the Parameters of Jump of a General Poisson-Diffusion Model," Scandinavian Actuarial Journal, 104, 42-52.

Martens, M. (2002), "Measuring and Forecasting S\&P500 Index Futures Volatility Using High-Frequency Data," Journal of Futures Markets, 22, 497-518.

Martens, M., (2004), “Estimating Unbiased and Precise Realized Covariances,” Manuscript, Erasmus University Rotterdam.

Martens, M., D. van Dijk and M. de Pooter (2004), "Modeling and Forecasting \&P500 Volatility: Long-Memory, Structural Breaks and Nonlinearity," Manuscript, Erasmus University Rotterdam.

Meddahi, N. (2002), “A Theoretical Comparison Between Integrated and Realized Volatility,” Journal of Applied Econometrics, 17, 479-508.

Merton, R.C. (1976), “Option Pricing when Underlying Stock Returns are Discontinuous,” Journal of Financial Economics, 3, 125-144. 
Merton, R.C. (1980), "On Estimating the Expected Return on the Market: An Exploratory Investigation," Journal of Financial Economics, 8, 323-361.

Müller, U.A., M.M. Dacorogna, R.B. Olsen, O.V. Puctet, M. Schwarz, and C. Morgenegg (1990), "Statistical Study of Foreign Exchange Rates, Empirical Evidence of a Price Change Scaling Law, and Intraday Analysis," Journal of Banking and Finance, 14, 1189-1208.

Müller, U.A., M.M. Dacorogna, R.D. Davé, R.B. Olsen, O.V. Puctet, and J. von Weizsäcker (1997), "Volatilities of Different Time Resolutions - Analyzing the Dynamics of Market Components," Journal of Empirical Finance, 4, 213-239.

Nelson, D.B. (1992), "Filtering and Forecasting with Misspecified ARCH Models I: Getting the Right Variance with the Wrong Model," Journal of Econometrics, 52, 61-90.

Nielsen, M.Ø. and P.H. Frederiksen (2004), “Finite Sample Accuracy of Integrated Volatility Estimators,” Manuscript, Cornell University.

O’Connell, P.E. (1971), “A Simple Stochastic Modelling of Hurst's Law,” Proceedings of International Symposium on Mathematical Models in Hydrology, 1, 169-187.

Oomen, R.C.A. (2002), “Modelling Realized Variance when Returns are Serially Correlated,” Manuscript, University of Warwick.

Oomen, R.C.A. (2004), "Properties of Realized Variance for a Pure Jump Process: Calendar Time Sampling versus Business Time Sampling," Manuscript, University of Warwick.

Pan, J. (2002), “the Jump-Risk Premia Implicit in Options: Evidence from an Integrated Time Series Study," Journal of Financial Economics, 63, 3-50.

Pong, S., M.B. Shackleton, S.J. Taylor and X. Xu (2004), "Forecasting Currency Volatility: A Comparison of Implied Volatilities and AR(FI)MA Models," Journal of Banking and Finance, forthcoming.

Robinson, P.M. (1991), “Testing for Strong Serial Correlation and Dynamic Conditional Heteroskedasticity in Multiple Regressions,” Journal of Econometrics, 47, 67-84.

Russell, J.R. and R.F. Engle (2005), “A Discrete-State Continuous-Time Model of Financial Transaction Prices and Times: The Autoregressive Conditional Multinomial - Autoregressive Duration Model," Journal of Business and Economic Statistics, 23, 166-180.

Rydberg, T. and N. Shephard (2003), “The Dynamics of Trade-by-Trade Price Movements,” Journal of Financial Econometrics, 1, 2-25.

Santa-Clara, P. and S. Yan (2004), "Jump and Volatility Risk and Risk Premia: A New Model and Lessons from S\&P500 Options,” Manuscript, UCLA.

Tiao, G.C. and R.S. Tsay (1994), "Some Advances in Non-Linear and Adaptive Modeling in Time Series," Journal of Forecasting, 14, 109-131.

Thomakos, D.D. and T. Wang (2003), "Realized Volatility in the Futures Market," Journal of Empirical Finance, 10, 321-353. 
Vlaar, P.J.G. and F.C. Palm (1993), "The Message in Weekly Exchange Rates in the European Monetary System: Mean Reversion, Conditional Heteroskedasticity, and Jumps," Journal of Business and Economic Statistics, $11,351-360$.

Zhang, L., Y. Aitt-Sahalia and P.A. Mykland (2005), "A Tale of Two Time Scales: Determining Integrated Volatility with Noisy High-Frequency Data,” Journal of the American Statistical Association, forthcoming.

Zhang, L. (2004), "Efficient Estimation of Stochastic Volatility Using Noisy Observations: A Multi-Scale Approach," Manuscript, Carnegie Mellon University.

Zhou, B. (1996), "High-Frequency Data and Volatility in Foreign Exchange Rates," Journal of Business and Economic Statistics, 14, 45-52. 
Table 1A

Summary Statistics for Daily DM/\$ Realized Volatilities and Jumps

\begin{tabular}{llllllc}
\hline & $R V_{t}$ & $R V_{t}^{1 / 2}$ & $\log \left(R V_{t}\right)$ & $J_{t}$ & $J_{t}^{1 / 2}$ & $\log \left(J_{t}+1\right)$ \\
Mean & 0.508 & 0.670 & -0.915 & 0.037 & 0.129 & 0.033 \\
St.Dev. & 0.453 & 0.245 & 0.657 & 0.110 & 0.142 & 0.072 \\
Skewness & 3.925 & 1.784 & 0.408 & 16.52 & 2.496 & 7.787 \\
Kurtosis & 26.88 & 8.516 & 3.475 & 434.2 & 18.20 & 108.5 \\
Min. & 0.052 & 0.227 & -2.961 & 0.000 & 0.000 & 0.000 \\
Max. & 5.245 & 2.290 & 1.657 & 3.566 & 1.889 & 1.519 \\
LB $_{10}$ & 3786 & 5714 & 7060 & 16.58 & 119.4 & 63.19 \\
\hline
\end{tabular}

Table 1B

Summary Statistics for Daily S\&P500 Realized Volatilities and Jumps

\begin{tabular}{llllllc}
\hline & $R V_{t}$ & $R V_{t}^{1 / 2}$ & $\log \left(R V_{t}\right)$ & $J_{t}$ & $J_{t}^{1 / 2}$ & $\log \left(J_{t}+1\right)$ \\
Mean & 1.137 & 0.927 & -0.400 & 0.164 & 0.232 & 0.097 \\
St.Dev. & 1.848 & 0.527 & 0.965 & 0.964 & 0.332 & 0.237 \\
Skewness & 7.672 & 2.545 & 0.375 & 20.68 & 5.585 & 6.386 \\
Kurtosis & 95.79 & 14.93 & 3.125 & 551.9 & 59.69 & 59.27 \\
Min. & 0.058 & 0.240 & -2.850 & 0.000 & 0.000 & 0.000 \\
Max. & 36.42 & 6.035 & 3.595 & 31.88 & 5.646 & 3.493 \\
LB $_{10}$ & 5750 & 12184 & 15992 & 558.0 & 1868 & 2295 \\
\hline
\end{tabular}

Table 1C

Summary Statistics for Daily U.S. T-Bond Realized Volatilities and Jumps

\begin{tabular}{llllllc}
\hline & $R V_{t}$ & $R V_{t}^{1 / 2}$ & $\log \left(R V_{t}\right)$ & $J_{t}$ & $J_{t}^{1 / 2}$ & $\log \left(J_{t}+1\right)$ \\
Mean & 0.286 & 0.506 & -1.468 & 0.036 & 0.146 & 0.033 \\
St.Dev. & 0.222 & 0.173 & 0.638 & 0.069 & 0.120 & 0.055 \\
Skewness & 3.051 & 1.352 & 0.262 & 8.732 & 1.667 & 5.662 \\
Kurtosis & 20.05 & 6.129 & 3.081 & 144.6 & 10.02 & 57.42 \\
Min. & 0.026 & 0.163 & -3.633 & 0.000 & 0.000 & 0.000 \\
Max. & 2.968 & 1.723 & 1.088 & 1.714 & 1.309 & 0.998 \\
LB $_{10}$ & 1022 & 1718 & 2238 & 20.53 & 34.10 & 26.95 \\
\hline
\end{tabular}

Key: The first six rows in each of the panels report the sample mean, standard deviation, skewness, and kurtosis, along with the sample minimum and maximum. The rows labeled $\mathrm{LB}_{10}$ give the Ljung-Box test statistic for up to tenth order serial correlation. The daily realized volatilities and jumps for the $\mathrm{DM} / \$$ in Panel A are constructed from five-minute returns spanning the period from December 1986 through June 1999, for a total of 3,045 daily observations. The daily realized volatilities and jumps for the S\&P500 and U.S. T-Bonds in Panels B and C are based on five-minute returns from January 1990 through December 2002, for a total of 3,213 observations. 
Table 2A

Daily, Weekly, and Monthly DM/\$ HAR-RV-J Regressions

$$
\begin{gathered}
R V_{t, t+h}=\beta_{0}+\beta_{D} R V_{t}+\beta_{W} R V_{t-5, t}+\beta_{M} R V_{t-22, t}+\beta_{J} J_{t}+\epsilon_{t, t+h} \\
\left(R V_{t, t+h}\right)^{1 / 2}=\beta_{0}+\beta_{D} R V_{t}^{1 / 2}+\beta_{W}\left(R V_{t-5, t}\right)^{1 / 2}+\beta_{M}\left(R V_{t-22, t}\right)^{1 / 2}+\beta_{J} J_{t}^{1 / 2}+\epsilon_{t, t+h} \\
\log \left(R V_{t, t+h}\right)=\beta_{0}+\beta_{D} \log \left(R V_{t}\right)+\beta_{W} \log \left(R V_{t-5, t}\right)+\beta_{M} \log \left(R V_{t-22, t}\right)+\beta_{J} \log \left(J_{t}+1\right)+\epsilon_{t, t+h}
\end{gathered}
$$

\begin{tabular}{|c|c|c|c|c|c|c|c|c|c|}
\hline \multirow[b]{2}{*}{$h$} & \multicolumn{3}{|c|}{$R V_{t, t+h}$} & \multicolumn{3}{|c|}{$\left(R V_{t, t+h}\right)^{1 / 2}$} & \multicolumn{3}{|c|}{$\log \left(R V_{t, t+h}\right)$} \\
\hline & 1 & 5 & 22 & 1 & 5 & 22 & 1 & 5 & 22 \\
\hline$\beta_{0}$ & $\begin{array}{c}0.083 \\
(0.015)\end{array}$ & $\begin{array}{c}0.132 \\
(0.018)\end{array}$ & $\begin{array}{c}0.231 \\
(0.025)\end{array}$ & $\begin{array}{c}0.096 \\
(0.015)\end{array}$ & $\begin{array}{c}0.159 \\
(0.021)\end{array}$ & $\begin{array}{c}0.293 \\
(0.034)\end{array}$ & $\begin{array}{l}-0.122 \\
(0.021)\end{array}$ & $\begin{array}{l}-0.142 \\
(0.030)\end{array}$ & $\begin{array}{l}-0.269 \\
(0.048)\end{array}$ \\
\hline$\beta_{D}$ & $\begin{array}{c}0.430 \\
(0.043)\end{array}$ & $\begin{array}{c}0.222 \\
(0.040)\end{array}$ & $\begin{array}{c}0.110 \\
(0.022)\end{array}$ & $\begin{array}{c}0.392 \\
(0.033)\end{array}$ & $\begin{array}{l}0.216 \\
(0.028)\end{array}$ & $\begin{array}{c}0.124 \\
(0.020)\end{array}$ & $\begin{array}{c}0.408 \\
(0.030)\end{array}$ & $\begin{array}{c}0.252 \\
(0.029)\end{array}$ & $\begin{array}{c}0.162 \\
(0.027)\end{array}$ \\
\hline$\beta_{W}$ & $\begin{array}{c}0.196 \\
(0.063)\end{array}$ & $\begin{array}{c}0.216 \\
(0.055)\end{array}$ & $\begin{array}{c}0.218 \\
(0.043)\end{array}$ & $\begin{array}{c}0.248 \\
(0.046)\end{array}$ & $\begin{array}{c}0.264 \\
(0.050)\end{array}$ & $\begin{array}{c}0.243 \\
(0.040)\end{array}$ & $\begin{array}{c}0.271 \\
(0.042)\end{array}$ & $\begin{array}{c}0.265 \\
(0.051)\end{array}$ & $\begin{array}{c}0.221 \\
(0.039)\end{array}$ \\
\hline$\beta_{M}$ & $\begin{array}{c}0.244 \\
(0.061)\end{array}$ & $\begin{array}{c}0.323 \\
(0.068)\end{array}$ & $\begin{array}{c}0.225 \\
(0.062)\end{array}$ & $\begin{array}{c}0.223 \\
(0.041)\end{array}$ & $\begin{array}{c}0.296 \\
(0.056)\end{array}$ & $\begin{array}{c}0.219 \\
(0.063)\end{array}$ & $\begin{array}{c}0.212 \\
(0.036)\end{array}$ & $\begin{array}{c}0.284 \\
(0.054)\end{array}$ & $\begin{array}{c}0.226 \\
(0.065)\end{array}$ \\
\hline$\beta_{J}$ & $\begin{array}{l}-0.486 \\
(0.096)\end{array}$ & $\begin{array}{l}-0.297 \\
(0.070)\end{array}$ & $\begin{array}{l}-0.166 \\
(0.056)\end{array}$ & $\begin{array}{l}-0.103 \\
(0.039)\end{array}$ & $\begin{array}{l}-0.047 \\
(0.031)\end{array}$ & $\begin{array}{l}-0.026 \\
(0.029)\end{array}$ & $\begin{array}{l}-0.762 \\
(0.161)\end{array}$ & $\begin{array}{l}-0.590 \\
(0.176)\end{array}$ & $\begin{array}{l}-0.395 \\
(0.178)\end{array}$ \\
\hline$R_{H A R-R V-J}^{2}$ & 0.364 & 0.417 & 0.353 & 0.431 & 0.472 & 0.386 & 0.476 & 0.502 & 0.407 \\
\hline$R_{H A R}^{2}$ & 0.252 & 0.261 & 0.215 & 0.261 & 0.272 & 0.225 & 0.160 & 0.159 & 0.138 \\
\hline
\end{tabular}

Key: The table reports the OLS estimates for daily $(\mathrm{h}=1)$ and overlapping weekly $(\mathrm{h}=5)$ and monthly $(\mathrm{h}=22)$ HAR-RV-J volatility forecast regressions. The realized volatilities and jumps are constructed from five-minute returns spanning the period from December 1986 through June 1999, for a total of 3,045 daily observations. The standard errors reported in parentheses are based on a Newey-West/Bartlett correction allowing for serial correlation of up to order $5(\mathrm{~h}=1), 10(\mathrm{~h}=5)$, and $44(\mathrm{~h}=22)$, respectively. The last two rows labeled $R_{\text {HAR-RV-J }}^{2}$ and $R_{H A R}^{2}$ are for the HAR-RV-J model and a "standard" HAR model with no jumps and with the realized volatilities on the right-hand-side of the regression replaced with the corresponding lagged daily, weekly, and monthly squared returns. 
Table 2B

Daily, Weekly, and Monthly S\&P500 HAR-RV-J Regressions

$$
\begin{gathered}
R V_{t, t+h}=\beta_{0}+\beta_{D} R V_{t}+\beta_{W} R V_{t-5, t}+\beta_{M} R V_{t-22, t}+\beta_{J} J_{t}+\epsilon_{t, t+h} \\
\left(R V_{t, t+h}\right)^{1 / 2}=\beta_{0}+\beta_{D} R V_{t}^{1 / 2}+\beta_{W}\left(R V_{t-5, t}\right)^{1 / 2}+\beta_{M}\left(R V_{t-22, t}\right)^{1 / 2}+\beta_{J} J_{t}^{1 / 2}+\epsilon_{t, t+h} \\
\log \left(R V_{t, t+h}\right)=\beta_{0}+\beta_{D} \log \left(R V_{t}\right)+\beta_{W} \log \left(R V_{t-5, t}\right)+\beta_{M} \log \left(R V_{t-22, t}\right)+\beta_{J} \log \left(J_{t}+1\right)+\epsilon_{t, t+h}
\end{gathered}
$$

\begin{tabular}{|c|c|c|c|c|c|c|c|c|c|}
\hline \multirow[b]{2}{*}{$h$} & \multicolumn{3}{|c|}{$R V_{t, t+h}$} & \multicolumn{3}{|c|}{$\left(R V_{t, t+h}\right)^{1 / 2}$} & \multicolumn{3}{|c|}{$\log \left(R V_{t, t+h}\right)$} \\
\hline & 1 & 5 & 22 & 1 & 5 & 22 & 1 & 5 & 22 \\
\hline$\beta_{0}$ & $\begin{array}{c}0.088 \\
(0.054)\end{array}$ & $\begin{array}{c}0.186 \\
(0.066)\end{array}$ & $\begin{array}{c}0.387 \\
(0.074)\end{array}$ & $\begin{array}{c}0.060 \\
(0.020)\end{array}$ & $\begin{array}{c}0.102 \\
(0.030)\end{array}$ & $\begin{array}{c}0.205 \\
(0.038)\end{array}$ & $\begin{array}{l}-0.065 \\
(0.015)\end{array}$ & $\begin{array}{c}0.001 \\
(0.019)\end{array}$ & $\begin{array}{c}0.022 \\
(0.036)\end{array}$ \\
\hline$\beta_{D}$ & $\begin{array}{c}0.341 \\
(0.094)\end{array}$ & $\begin{array}{c}0.220 \\
(0.064)\end{array}$ & $\begin{array}{c}0.109 \\
(0.040)\end{array}$ & $\begin{array}{c}0.375 \\
(0.041)\end{array}$ & $\begin{array}{c}0.262 \\
(0.038)\end{array}$ & $\begin{array}{c}0.169 \\
(0.029)\end{array}$ & $\begin{array}{c}0.348 \\
(0.028)\end{array}$ & $\begin{array}{l}0.235 \\
(0.025)\end{array}$ & $\begin{array}{c}0.164 \\
(0.024)\end{array}$ \\
\hline$\beta_{W}$ & $\begin{array}{c}0.485 \\
(0.111)\end{array}$ & $\begin{array}{l}0.430 \\
(0.097)\end{array}$ & $\begin{array}{c}0.287 \\
(0.093)\end{array}$ & $\begin{array}{c}0.354 \\
(0.064)\end{array}$ & $\begin{array}{c}0.395 \\
(0.067)\end{array}$ & $\begin{array}{c}0.291 \\
(0.071)\end{array}$ & $\begin{array}{c}0.329 \\
(0.041)\end{array}$ & $\begin{array}{c}0.363 \\
(0.050)\end{array}$ & $\begin{array}{c}0.260 \\
(0.049)\end{array}$ \\
\hline$\beta_{M}$ & $\begin{array}{c}0.165 \\
(0.067)\end{array}$ & $\begin{array}{c}0.220 \\
(0.079)\end{array}$ & $\begin{array}{c}0.279 \\
(0.088)\end{array}$ & $\begin{array}{c}0.239 \\
(0.040)\end{array}$ & $\begin{array}{c}0.270 \\
(0.058)\end{array}$ & $\begin{array}{c}0.357 \\
(0.069)\end{array}$ & $\begin{array}{c}0.285 \\
(0.031)\end{array}$ & $\begin{array}{c}0.334 \\
(0.046)\end{array}$ & $\begin{array}{c}0.444 \\
(0.054)\end{array}$ \\
\hline$\beta_{J}$ & $\begin{array}{l}-0.472 \\
(0.102)\end{array}$ & $\begin{array}{l}-0.228 \\
(0.078)\end{array}$ & $\begin{array}{l}-0.075 \\
(0.067)\end{array}$ & $\begin{array}{l}-0.213 \\
(0.051)\end{array}$ & $\begin{array}{l}-0.134 \\
(0.041)\end{array}$ & $\begin{array}{l}-0.054 \\
(0.046)\end{array}$ & $\begin{array}{l}-0.260 \\
(0.062)\end{array}$ & $\begin{array}{l}-0.187 \\
(0.064)\end{array}$ & $\begin{array}{l}-0.105 \\
(0.080)\end{array}$ \\
\hline$R_{H A R-R V-J}^{2}$ & 0.415 & 0.569 & 0.474 & 0.604 & 0.697 & 0.634 & 0.693 & 0.761 & 0.727 \\
\hline$R_{H A R}^{2}$ & 0.248 & 0.239 & 0.159 & 0.322 & 0.320 & 0.275 & 0.197 & 0.219 & 0.218 \\
\hline
\end{tabular}

Key: The table reports the OLS estimates for daily $(\mathrm{h}=1)$ and overlapping weekly $(\mathrm{h}=5)$, and monthly $(\mathrm{h}=22)$ HAR-RV-J volatility forecast regressions. The realized volatilities and jumps are constructed from five-minute returns spanning the period from January 1990 through December 2002, for a total of 3,213 daily observations. The standard errors reported in parentheses are based on a Newey-West/Bartlett correction allowing for serial correlation of up to order $5(\mathrm{~h}=1), 10(\mathrm{~h}=5)$, and $44(\mathrm{~h}=22)$, respectively. The last two rows labeled $R_{\text {HAR-RV-J }}^{2}$ and $R_{H A R}^{2}$ are for the HAR-RV-J model and a "standard" HAR model with no jumps and with the realized volatilities on the right-hand-side of the regression replaced with the corresponding lagged daily, weekly, and monthly squared returns. 
Table 2C

Daily, Weekly, and Monthly U.S. T-Bond HAR-RV-J Regressions

$$
\begin{gathered}
R V_{t, t+h}=\beta_{0}+\beta_{D} R V_{t}+\beta_{W} R V_{t-5, t}+\beta_{M} R V_{t-22, t}+\beta_{J} J_{t}+\epsilon_{t, t+h} \\
\left(R V_{t, t+h}\right)^{1 / 2}=\beta_{0}+\beta_{D} R V_{t}^{1 / 2}+\beta_{W}\left(R V_{t-5, t}\right)^{1 / 2}+\beta_{M}\left(R V_{t-22, t}\right)^{1 / 2}+\beta_{J} J_{t}^{1 / 2}+\epsilon_{t, t+h} \\
\log \left(R V_{t, t+h}\right)=\beta_{0}+\beta_{D} \log \left(R V_{t}\right)+\beta_{W} \log \left(R V_{t-5, t}\right)+\beta_{M} \log \left(R V_{t-22, t}+\beta_{J} \log \left(J_{t}+1\right)+\epsilon_{t, t+h}\right.
\end{gathered}
$$

\begin{tabular}{|c|c|c|c|c|c|c|c|c|c|}
\hline \multirow[b]{2}{*}{$h$} & \multicolumn{3}{|c|}{$R V_{t, t+h}$} & \multicolumn{3}{|c|}{$\left(R V_{t, t+h}\right)^{1 / 2}$} & \multicolumn{3}{|c|}{$\log \left(R V_{t, t+h}\right)$} \\
\hline & 1 & 5 & 22 & 1 & 5 & 22 & 1 & 5 & 22 \\
\hline$\beta_{0}$ & $\begin{array}{c}0.077 \\
(0.012)\end{array}$ & $\begin{array}{c}0.088 \\
(0.013)\end{array}$ & $\begin{array}{c}0.126 \\
(0.017)\end{array}$ & $\begin{array}{c}0.118 \\
(0.017)\end{array}$ & $\begin{array}{c}0.152 \\
(0.021)\end{array}$ & $\begin{array}{c}0.222 \\
(0.031)\end{array}$ & $\begin{array}{l}-0.353 \\
(0.044)\end{array}$ & $\begin{array}{l}-0.323 \\
(0.051)\end{array}$ & $\begin{array}{l}-0.473 \\
(0.080)\end{array}$ \\
\hline$\beta_{D}$ & $\begin{array}{c}0.074 \\
(0.031)\end{array}$ & $\begin{array}{c}0.084 \\
(0.016)\end{array}$ & $\begin{array}{c}0.044 \\
(0.011)\end{array}$ & $\begin{array}{c}0.066 \\
(0.026)\end{array}$ & $\begin{array}{c}0.082 \\
(0.014)\end{array}$ & $\begin{array}{c}0.044 \\
(0.009)\end{array}$ & $\begin{array}{c}0.104 \\
(0.024)\end{array}$ & $\begin{array}{l}0.100 \\
(0.015)\end{array}$ & $\begin{array}{c}0.063 \\
(0.012)\end{array}$ \\
\hline$\beta_{W}$ & $\begin{array}{c}0.317 \\
(0.050)\end{array}$ & $\begin{array}{c}0.217 \\
(0.043)\end{array}$ & $\begin{array}{c}0.160 \\
(0.040)\end{array}$ & $\begin{array}{c}0.319 \\
(0.045)\end{array}$ & $\begin{array}{c}0.215 \\
(0.039)\end{array}$ & $\begin{array}{c}0.162 \\
(0.036)\end{array}$ & $\begin{array}{c}0.324 \\
(0.043)\end{array}$ & $\begin{array}{c}0.206 \\
(0.039)\end{array}$ & $\begin{array}{c}0.154 \\
(0.032)\end{array}$ \\
\hline$\beta_{M}$ & $\begin{array}{c}0.358 \\
(0.056)\end{array}$ & $\begin{array}{c}0.416 \\
(0.055)\end{array}$ & $\begin{array}{c}0.373 \\
(0.070)\end{array}$ & $\begin{array}{c}0.369 \\
(0.046)\end{array}$ & $\begin{array}{c}0.429 \\
(0.051)\end{array}$ & $\begin{array}{c}0.388 \\
(0.068)\end{array}$ & $\begin{array}{c}0.379 \\
(0.046)\end{array}$ & $\begin{array}{l}0.440 \\
(0.053)\end{array}$ & $\begin{array}{c}0.395 \\
(0.070)\end{array}$ \\
\hline$\beta_{J}$ & $\begin{array}{l}-0.152 \\
(0.099)\end{array}$ & $\begin{array}{l}-0.202 \\
(0.042)\end{array}$ & $\begin{array}{l}-0.140 \\
(0.034)\end{array}$ & $\begin{array}{l}-0.047 \\
(0.032)\end{array}$ & $\begin{array}{l}-0.062 \\
(0.018)\end{array}$ & $\begin{array}{l}-0.042 \\
(0.015)\end{array}$ & $\begin{array}{l}-0.869 \\
(0.240)\end{array}$ & $\begin{array}{l}-0.693 \\
(0.129)\end{array}$ & $\begin{array}{l}-0.545 \\
(0.123)\end{array}$ \\
\hline$R_{H A R-R V-J}^{2}$ & 0.130 & 0.308 & 0.340 & 0.171 & 0.332 & 0.360 & 0.200 & 0.351 & 0.379 \\
\hline$R_{H A R}^{2}$ & 0.067 & 0.128 & 0.105 & 0.072 & 0.117 & 0.093 & 0.025 & 0.042 & 0.035 \\
\hline
\end{tabular}

Key: The table reports the OLS estimates for daily $(\mathrm{h}=1)$ and overlapping weekly $(\mathrm{h}=5)$ and monthly $(\mathrm{h}=22)$ HAR-RV-J volatility forecast regressions. The realized volatilities and jumps are constructed from five-minute returns spanning the period from January 1990 through December 2002, for a total of 3,213 daily observations. The standard errors reported in parentheses are based on a Newey-West/Bartlett correction allowing for serial correlation of up to order $5(\mathrm{~h}=1), 10(\mathrm{~h}=5)$, and $44(\mathrm{~h}=22)$, respectively. The last two rows labeled $R_{\text {HAR-RV-J }}^{2}$ and $R_{H A R}^{2}$ are for the HAR-RV-J model and a "standard" HAR model with no jumps and with the realized volatilities on the right-hand-side of the regression replaced with the corresponding lagged daily, weekly, and monthly squared returns. 
Table 3A

Summary Statistics for Significant Daily DM/\$ Jumps

\begin{tabular}{lccccc}
\hline$\alpha$ & 0.500 & 0.950 & 0.990 & 0.999 & 0.9999 \\
Prop. & 0.859 & 0.409 & 0.254 & 0.137 & 0.083 \\
Mean. & 0.059 & 0.047 & 0.037 & 0.028 & 0.021 \\
St.Dev. & 0.136 & 0.137 & 0.135 & 0.131 & 0.127 \\
LB ${ }_{10}, J_{t, \alpha}$ & 65.49 & 26.30 & 6.197 & 3.129 & 2.414 \\
$\mathrm{LR}, I\left(J_{t, \alpha}>0\right)$ & 0.746 & 2.525 & 0.224 & 0.994 & 0.776 \\
$\mathrm{LB}_{10}, D_{t, \alpha}+$ & 10.78 & 9.900 & 7.821 & 6.230 & 19.95 \\
$\mathrm{LB}_{10}, J_{t, \alpha}^{+}$ & 73.62 & 116.4 & 94.19 & 87.69 & 34.57 \\
\hline
\end{tabular}

Table 3B

Summary Statistics for Significant Daily S\&P500 Jumps

\begin{tabular}{lccccc}
\hline$\alpha$ & 0.500 & 0.950 & 0.990 & 0.999 & 0.9999 \\
Prop. & 0.737 & 0.255 & 0.141 & 0.076 & 0.051 \\
Mean. & 0.163 & 0.132 & 0.111 & 0.095 & 0.086 \\
St.Dev. & 0.961 & 0.961 & 0.958 & 0.953 & 0.950 \\
LB ${ }_{10}, J_{t, \alpha}$ & 300.6 & 271.9 & 266.4 & 260.9 & 221.6 \\
$\mathrm{LR}, I\left(J_{t, \alpha}>0\right)$ & 2.415 & 1.483 & 12.83 & 8.418 & 7.824 \\
$\mathrm{LB}_{10}, D_{t, \alpha}$ & 50.83 & 31.47 & 22.67 & 36.18 & 49.25 \\
$\mathrm{LB}_{10}, J_{t, \alpha}^{+}$ & 320.8 & 146.0 & 77.06 & 35.11 & 25.49 \\
\hline
\end{tabular}

Table 3C

Summary Statistics for Significant Daily U.S. T-Bond Jumps

\begin{tabular}{|c|c|c|c|c|c|}
\hline$\alpha$ & 0.500 & 0.950 & 0.990 & 0.999 & 0.9999 \\
\hline Prop. & 0.860 & 0.418 & 0.254 & 0.132 & 0.076 \\
\hline Mean. & 0.048 & 0.038 & 0.030 & 0.021 & 0.016 \\
\hline St.Dev. & 0.094 & 0.096 & 0.096 & 0.090 & 0.085 \\
\hline $\mathrm{LB}_{10}, J_{t, \alpha}$ & 30.34 & 30.37 & 27.85 & 19.80 & 18.85 \\
\hline $\mathrm{LR}, I\left(J_{t, \alpha}>0\right)$ & 4.746 & 21.62 & 13.69 & 3.743 & 1.913 \\
\hline $\mathrm{LB}_{10}, D_{t, \alpha}$ & 45.55 & 100.1 & 59.86 & 103.3 & 81.42 \\
\hline $\mathrm{LB}_{10}, J_{t, \alpha}^{+}$ & 21.23 & 17.18 & 15.18 & 9.090 & 11.98 \\
\hline
\end{tabular}

Key: The significant jumps for each of the three market, $J_{t, \alpha}$, are determined by equation (19) along with the staggered bi-power and tri-power variation measures in equations (23) and (23), respectively. The first row in each of the panels gives the proportion significant jump days for each of the different $\alpha$ 's. The next two rows report the corresponding mean and standard deviation of the jump series, while the row labeled $\mathrm{LB}_{10}, J_{t, \alpha}$ gives the Ljung-Box tests for up to tenth order serial correlation. LR, $I\left(J_{t, \alpha}>0\right)$ denotes the Likelihood Ratio test for i.i.d. jump occurrences against a first Markov chain, while $\mathrm{LB}_{10}, D_{t, \alpha}$, and $\mathrm{LB}_{10}, J_{t, \alpha}{ }^{+}$refer to the Ljung-Box tests for serial correlation in the corresponding durations, or times between jumps, and the sizes of the significant jumps, respectively. 
Table 4A

Daily, Weekly, and Monthly DM/\$ HAR-RV-CJ Regressions

$$
\begin{gathered}
R V_{t, t+h}=\beta_{0}+\beta_{C D} C_{t}+\beta_{C W} C_{t-5, t}+\beta_{C M} C_{t-22, t}+\beta_{J D} J_{t}+\beta_{J W} J_{t-5, t}+\beta_{J M} J_{t-22, t}+\epsilon_{t, t+h} \\
\left(R V_{t, t+h}\right)^{1 / 2}=\beta_{0}+\beta_{C D} C_{t}^{1 / 2}+\beta_{C W}\left(C_{t-5, t}\right)^{1 / 2}+\beta_{C M}\left(C_{t-22, t}\right)^{1 / 2}+\beta_{J D} J_{t}^{1 / 2}+\beta_{J W}\left(J_{t-5, t}\right)^{1 / 2}+\beta_{J M}\left(J_{t-22, t}\right)^{1 / 2}+\epsilon_{t, t+h} \\
\log \left(R V_{t, t+h}\right)=\beta_{0}+\beta_{C D} \log \left(C_{t}\right)+\beta_{C W} \log \left(C_{t-5, t}\right)+\beta_{C M} \log \left(C_{t-22, t}\right)+ \\
\beta_{J D} \log \left(J_{t}+1\right)+\beta_{J W} \log \left(J_{t-5, t}+1\right)+\beta_{J M} \log \left(C_{t-22, t}+1\right)+\epsilon_{t, t+h}
\end{gathered}
$$

\begin{tabular}{|c|c|c|c|c|c|c|c|c|c|}
\hline \multirow[b]{2}{*}{$h$} & \multicolumn{3}{|c|}{$R V_{t, t+h}$} & \multicolumn{3}{|c|}{$\left(R V_{t, t+h}\right)^{1 / 2}$} & \multicolumn{3}{|c|}{$\log \left(R V_{t, t+h}\right)$} \\
\hline & 1 & 5 & 22 & 1 & 5 & 22 & 1 & 5 & 22 \\
\hline$\beta_{0}$ & $\begin{array}{c}0.083 \\
(0.015)\end{array}$ & $\begin{array}{c}0.131 \\
(0.018)\end{array}$ & $\begin{array}{c}0.231 \\
(0.025)\end{array}$ & $\begin{array}{c}0.096 \\
(0.015)\end{array}$ & $\begin{array}{c}0.158 \\
(0.021)\end{array}$ & $\begin{array}{c}0.292 \\
(0.034)\end{array}$ & $\begin{array}{l}-0.095 \\
(0.024)\end{array}$ & $\begin{array}{l}-0.114 \\
(0.036)\end{array}$ & $\begin{array}{l}-0.249 \\
(0.057)\end{array}$ \\
\hline$\beta_{C D}$ & $\begin{array}{c}0.407 \\
(0.044)\end{array}$ & $\begin{array}{c}0.210 \\
(0.040)\end{array}$ & $\begin{array}{c}0.101 \\
(0.021)\end{array}$ & $\begin{array}{c}0.397 \\
(0.032)\end{array}$ & $\begin{array}{c}0.222 \\
(0.029)\end{array}$ & $\begin{array}{c}0.127 \\
(0.019)\end{array}$ & $\begin{array}{c}0.369 \\
(0.026)\end{array}$ & $\begin{array}{c}0.205 \\
(0.021)\end{array}$ & $\begin{array}{c}0.130 \\
(0.016)\end{array}$ \\
\hline$\beta_{C W}$ & $\begin{array}{c}0.256 \\
(0.077)\end{array}$ & $\begin{array}{c}0.271 \\
(0.054)\end{array}$ & $\begin{array}{c}0.259 \\
(0.046)\end{array}$ & $\begin{array}{c}0.264 \\
(0.048)\end{array}$ & $\begin{array}{c}0.289 \\
(0.051)\end{array}$ & $\begin{array}{c}0.264 \\
(0.042)\end{array}$ & $\begin{array}{c}0.295 \\
(0.039)\end{array}$ & $\begin{array}{c}0.318 \\
(0.048)\end{array}$ & $\begin{array}{c}0.258 \\
(0.040)\end{array}$ \\
\hline$\beta_{C M}$ & $\begin{array}{c}0.226 \\
(0.072)\end{array}$ & $\begin{array}{c}0.308 \\
(0.078)\end{array}$ & $\begin{array}{c}0.217 \\
(0.074)\end{array}$ & $\begin{array}{c}0.212 \\
(0.044)\end{array}$ & $\begin{array}{c}0.281 \\
(0.060)\end{array}$ & $\begin{array}{c}0.205 \\
(0.068)\end{array}$ & $\begin{array}{c}0.217 \\
(0.036)\end{array}$ & $\begin{array}{l}0.270 \\
(0.055)\end{array}$ & $\begin{array}{c}0.213 \\
(0.071)\end{array}$ \\
\hline$\beta_{J D}$ & $\begin{array}{c}0.096 \\
(0.089)\end{array}$ & $\begin{array}{c}0.006 \\
(0.040)\end{array}$ & $\begin{array}{l}-0.002 \\
(0.017)\end{array}$ & $\begin{array}{c}0.022 \\
(0.027)\end{array}$ & $\begin{array}{c}0.001 \\
(0.017)\end{array}$ & $\begin{array}{c}0.003 \\
(0.010)\end{array}$ & $\begin{array}{c}0.043 \\
(0.111)\end{array}$ & $\begin{array}{c}0.024 \\
(0.076)\end{array}$ & $\begin{array}{l}-0.004 \\
(0.044)\end{array}$ \\
\hline$\beta_{J W}$ & $\begin{array}{l}-0.191 \\
(0.168)\end{array}$ & $\begin{array}{l}-0.179 \\
(0.199)\end{array}$ & $\begin{array}{l}-0.073 \\
(0.125)\end{array}$ & $\begin{array}{l}-0.006 \\
(0.033)\end{array}$ & $\begin{array}{c}0.001 \\
(0.044)\end{array}$ & $\begin{array}{c}0.002 \\
(0.028)\end{array}$ & $\begin{array}{l}-0.076 \\
(0.239)\end{array}$ & $\begin{array}{l}-0.317 \\
(0.327)\end{array}$ & $\begin{array}{l}-0.127 \\
(0.242)\end{array}$ \\
\hline$\beta_{J M}$ & $\begin{array}{l}-0.001 \\
(0.329)\end{array}$ & $\begin{array}{c}0.055 \\
(0.460)\end{array}$ & $\begin{array}{l}-0.014 \\
(0.604)\end{array}$ & $\begin{array}{l}-0.034 \\
(0.057)\end{array}$ & $\begin{array}{l}-0.011 \\
(0.087)\end{array}$ & $\begin{array}{c}0.014 \\
(0.127)\end{array}$ & $\begin{array}{l}-0.690 \\
(0.408)\end{array}$ & $\begin{array}{l}-0.301 \\
(0.668)\end{array}$ & $\begin{array}{l}-0.261 \\
(0.990)\end{array}$ \\
\hline$R_{H A R-R V-C J}^{2}$ & 0.368 & 0.427 & 0.361 & 0.443 & 0.486 & 0.397 & 0.485 & 0.514 & 0.415 \\
\hline
\end{tabular}

Key: The table reports the OLS estimates for daily $(\mathrm{h}=1)$ and overlapping weekly $(\mathrm{h}=5)$ and monthly $(\mathrm{h}=22)$ HAR-RV-CJ volatility forecast regressions. All of the realized volatility measures are constructed from fiveminute returns spanning the period from December 1986 through June 1999, for a total of 3,045 daily observations. The weekly and monthly measures are the scaled sums of the corresponding daily measures. The significant daily jump and continuous sample path variability measures are based on equations (19) and (20), respectively, along with the staggered power variation measures in equations (22) and (23), using a critical value of $\alpha=0.999$. The standard errors reported in parentheses are based on a Newey-West/Bartlett correction allowing for serial correlation of up to order $5(\mathrm{~h}=1), 10(\mathrm{~h}=5)$, and $44(\mathrm{~h}=22)$, respectively. 
Table 4B

Daily, Weekly, and Monthly S\&P500 HAR-RV-CJ Regressions

$$
\begin{gathered}
R V_{t, t+h}=\beta_{0}+\beta_{C D} C_{t}+\beta_{C W} C_{t-5, t}+\beta_{C M} C_{t-22, t}+\beta_{J D} J_{t}+\beta_{J W} J_{t-5, t}+\beta_{J M} J_{t-22, t}+\epsilon_{t, t+h} \\
\left(R V_{t, t+h}\right)^{1 / 2}=\beta_{0}+\beta_{C D} C_{t}^{1 / 2}+\beta_{C W}\left(C_{t-5, t}\right)^{1 / 2}+\beta_{C M}\left(C_{t-22, t}\right)^{1 / 2}+\beta_{J D} J_{t}^{1 / 2}+\beta_{J W}\left(J_{t-5, t}\right)^{1 / 2}+\beta_{J M}\left(J_{t-22, t}\right)^{1 / 2}+\epsilon_{t, t+h} \\
\log \left(R V_{t, t+h}\right)=\beta_{0}+\beta_{C D} \log \left(C_{t}\right)+\beta_{C W} \log \left(C_{t-5, t}\right)+\beta_{C M} \log \left(C_{t-22, t}\right)+ \\
\beta_{J D} \log \left(J_{t}+1\right)+\beta_{J W} \log \left(J_{t-5, t}+1\right)+\beta_{J M} \log \left(C_{t-22, t}+1\right)+\epsilon_{t, t+h}
\end{gathered}
$$

\begin{tabular}{|c|c|c|c|c|c|c|c|c|c|}
\hline \multirow[b]{2}{*}{$h$} & \multicolumn{3}{|c|}{$R V_{t, t+h}$} & \multicolumn{3}{|c|}{$\left(R V_{t, t+h}\right)^{1 / 2}$} & \multicolumn{3}{|c|}{$\log \left(R V_{t, t+h}\right)$} \\
\hline & 1 & 5 & 22 & 1 & 5 & 22 & 1 & 5 & 22 \\
\hline$\beta_{0}$ & $\begin{array}{c}0.143 \\
(0.040)\end{array}$ & $\begin{array}{c}0.222 \\
(0.057)\end{array}$ & $\begin{array}{c}0.393 \\
(0.075)\end{array}$ & $\begin{array}{c}0.062 \\
(0.018)\end{array}$ & $\begin{array}{c}0.103 \\
(0.028)\end{array}$ & $\begin{array}{c}0.202 \\
(0.037)\end{array}$ & $\begin{array}{l}-0.063 \\
(0.013)\end{array}$ & $\begin{array}{c}0.003 \\
(0.019)\end{array}$ & $\begin{array}{c}0.026 \\
(0.036)\end{array}$ \\
\hline$\beta_{C D}$ & $\begin{array}{c}0.356 \\
(0.067)\end{array}$ & $\begin{array}{c}0.224 \\
(0.043)\end{array}$ & $\begin{array}{c}0.135 \\
(0.023)\end{array}$ & $\begin{array}{c}0.381 \\
(0.041)\end{array}$ & $\begin{array}{c}0.262 \\
(0.031)\end{array}$ & $\begin{array}{c}0.183 \\
(0.024)\end{array}$ & $\begin{array}{c}0.320 \\
(0.028)\end{array}$ & $\begin{array}{c}0.224 \\
(0.022)\end{array}$ & $\begin{array}{c}0.162 \\
(0.020)\end{array}$ \\
\hline$\beta_{C W}$ & $\begin{array}{c}0.426 \\
(0.120)\end{array}$ & $\begin{array}{c}0.413 \\
(0.114)\end{array}$ & $\begin{array}{c}0.204 \\
(0.070)\end{array}$ & $\begin{array}{c}0.367 \\
(0.063)\end{array}$ & $\begin{array}{c}0.413 \\
(0.072)\end{array}$ & $\begin{array}{c}0.272 \\
(0.061)\end{array}$ & $\begin{array}{c}0.368 \\
(0.043)\end{array}$ & $\begin{array}{c}0.383 \\
(0.053)\end{array}$ & $\begin{array}{c}0.274 \\
(0.049)\end{array}$ \\
\hline$\beta_{C M}$ & $\begin{array}{c}0.111 \\
(0.063)\end{array}$ & $\begin{array}{c}0.168 \\
(0.076)\end{array}$ & $\begin{array}{c}0.319 \\
(0.070)\end{array}$ & $\begin{array}{c}0.163 \\
(0.042)\end{array}$ & $\begin{array}{c}0.206 \\
(0.062)\end{array}$ & $\begin{array}{c}0.322 \\
(0.065)\end{array}$ & $\begin{array}{c}0.246 \\
(0.032)\end{array}$ & $\begin{array}{c}0.297 \\
(0.049)\end{array}$ & $\begin{array}{c}0.403 \\
(0.056)\end{array}$ \\
\hline$\beta_{J D}$ & $\begin{array}{l}-0.153 \\
(0.063)\end{array}$ & $\begin{array}{l}-0.016 \\
(0.049)\end{array}$ & $\begin{array}{c}0.005 \\
(0.022)\end{array}$ & $\begin{array}{l}-0.043 \\
(0.043)\end{array}$ & $\begin{array}{l}-0.013 \\
(0.027)\end{array}$ & $\begin{array}{c}0.005 \\
(0.017)\end{array}$ & $\begin{array}{l}-0.006 \\
(0.066)\end{array}$ & $\begin{array}{l}-0.027 \\
(0.049)\end{array}$ & $\begin{array}{c}0.018 \\
(0.031)\end{array}$ \\
\hline$\beta_{J W}$ & $\begin{array}{c}0.465 \\
(0.233)\end{array}$ & $\begin{array}{c}0.362 \\
(0.205)\end{array}$ & $\begin{array}{c}0.456 \\
(0.287)\end{array}$ & $\begin{array}{c}0.082 \\
(0.071)\end{array}$ & $\begin{array}{c}0.096 \\
(0.075)\end{array}$ & $\begin{array}{c}0.132 \\
(0.113)\end{array}$ & $\begin{array}{c}0.062 \\
(0.105)\end{array}$ & $\begin{array}{l}0.163 \\
(0.126)\end{array}$ & $\begin{array}{c}0.198 \\
(0.176)\end{array}$ \\
\hline$\beta_{J M}$ & $\begin{array}{c}0.355 \\
(0.304)\end{array}$ & $\begin{array}{c}0.458 \\
(0.448)\end{array}$ & $\begin{array}{c}0.215 \\
(0.202)\end{array}$ & $\begin{array}{c}0.133 \\
(0.054)\end{array}$ & $\begin{array}{c}0.170 \\
(0.084)\end{array}$ & $\begin{array}{l}0.190 \\
(0.105)\end{array}$ & $\begin{array}{c}0.207 \\
(0.085)\end{array}$ & $\begin{array}{c}0.233 \\
(0.136)\end{array}$ & $\begin{array}{c}0.246 \\
(0.201)\end{array}$ \\
\hline$R_{H A R-R V-C J}^{2}$ & 0.421 & 0.574 & 0.478 & 0.613 & 0.700 & 0.639 & 0.696 & 0.763 & 0.722 \\
\hline
\end{tabular}

Key: The table reports the OLS estimates for daily $(\mathrm{h}=1)$ and overlapping weekly $(\mathrm{h}=5)$ and monthly $(\mathrm{h}=22)$ HAR-RV-CJ volatility forecast regressions. All of the realized volatility measures are constructed from fiveminute returns spanning the period from January 1990 through December 2002, for a total of 3,213 daily observations. The weekly and monthly measures are the scaled sums of the corresponding daily measures. The significant daily jump and continuous sample path variability measures are based on equations (19) and (20), respectively, along with the staggered power variation measures in equations (22) and (23), using a critical value of $\alpha=0.999$. The standard errors reported in parentheses are based on a Newey-West/Bartlett correction allowing for serial correlation of up to order $5(\mathrm{~h}=1), 10(\mathrm{~h}=5)$, and $44(\mathrm{~h}=22)$, respectively. 
Table 4C

Daily, Weekly, and Monthly U.S. T-Bond HAR-RV-CJ Regressions

$$
\begin{gathered}
R V_{t, t+h}=\beta_{0}+\beta_{C D} C_{t}+\beta_{C W} C_{t-5, t}+\beta_{C M} C_{t-22, t}+\beta_{J D} J_{t}+\beta_{J W} J_{t-5, t}+\beta_{J M} J_{t-22, t}+\epsilon_{t, t+h} \\
\left(R V_{t, t+h}\right)^{1 / 2}=\beta_{0}+\beta_{C D} C_{t}^{1 / 2}+\beta_{C W}\left(C_{t-5, t}\right)^{1 / 2}+\beta_{C M}\left(C_{t-22, t}\right)^{1 / 2}+\beta_{J D} J_{t}^{1 / 2}+\beta_{J W}\left(J_{t-5, t}\right)^{1 / 2}+\beta_{J M}\left(J_{t-22, t}\right)^{1 / 2}+\epsilon_{t, t+h} \\
\log \left(R V_{t, t+h}\right)=\beta_{0}+\beta_{C D} \log \left(C_{t}\right)+\beta_{C W} \log \left(C_{t-5, t}\right)+\beta_{C M} \log \left(C_{t-22, t}\right)+ \\
\beta_{J D} \log \left(J_{t}+1\right)+\beta_{J W} \log \left(J_{t-5, t}+1\right)+\beta_{J M} \log \left(C_{t-22, t}+1\right)+\epsilon_{t, t+h}
\end{gathered}
$$

\begin{tabular}{|c|c|c|c|c|c|c|c|c|c|}
\hline \multirow[b]{2}{*}{ 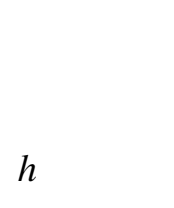 } & \multicolumn{3}{|c|}{$R V_{t, t+h}$} & \multicolumn{3}{|c|}{$\left(R V_{t, t+h}\right)^{1 / 2}$} & \multicolumn{3}{|c|}{$\log \left(R V_{t, t+h}\right)$} \\
\hline & 1 & 5 & 22 & 1 & 5 & 22 & 1 & 5 & 22 \\
\hline$\beta_{0}$ & $\begin{array}{c}0.085 \\
(0.011)\end{array}$ & $\begin{array}{c}0.095 \\
(0.012)\end{array}$ & $\begin{array}{c}0.133 \\
(0.017)\end{array}$ & $\begin{array}{c}0.133 \\
(0.016)\end{array}$ & $\begin{array}{c}0.166 \\
(0.019)\end{array}$ & $\begin{array}{c}0.236 \\
(0.031)\end{array}$ & $\begin{array}{l}-0.337 \\
(0.040)\end{array}$ & $\begin{array}{l}-0.335 \\
(0.052)\end{array}$ & $\begin{array}{c}-0.473 \\
(0.079)\end{array}$ \\
\hline$\beta_{C D}$ & $\begin{array}{c}0.107 \\
(0.031)\end{array}$ & $\begin{array}{c}0.064 \\
(0.015)\end{array}$ & $\begin{array}{c}0.031 \\
(0.006)\end{array}$ & $\begin{array}{c}0.087 \\
(0.025)\end{array}$ & $\begin{array}{c}0.069 \\
(0.013)\end{array}$ & $\begin{array}{c}0.034 \\
(0.006)\end{array}$ & $\begin{array}{c}0.091 \\
(0.022)\end{array}$ & $\begin{array}{c}0.068 \\
(0.012)\end{array}$ & $\begin{array}{c}0.036 \\
(0.007)\end{array}$ \\
\hline$\beta_{C W}$ & $\begin{array}{c}0.299 \\
(0.051)\end{array}$ & $\begin{array}{c}0.238 \\
(0.047)\end{array}$ & $\begin{array}{c}0.196 \\
(0.037)\end{array}$ & $\begin{array}{c}0.306 \\
(0.045)\end{array}$ & $\begin{array}{c}0.223 \\
(0.042)\end{array}$ & $\begin{array}{c}0.180 \\
(0.033)\end{array}$ & $\begin{array}{c}0.297 \\
(0.043)\end{array}$ & $\begin{array}{c}0.203 \\
(0.042)\end{array}$ & $\begin{array}{c}0.168 \\
(0.030)\end{array}$ \\
\hline$\beta_{C M}$ & $\begin{array}{c}0.366 \\
(0.062)\end{array}$ & $\begin{array}{c}0.426 \\
(0.062)\end{array}$ & $\begin{array}{c}0.369 \\
(0.068)\end{array}$ & $\begin{array}{c}0.367 \\
(0.048)\end{array}$ & $\begin{array}{c}0.428 \\
(0.055)\end{array}$ & $\begin{array}{c}0.380 \\
(0.065)\end{array}$ & $\begin{array}{c}0.389 \\
(0.046)\end{array}$ & $\begin{array}{c}0.439 \\
(0.055)\end{array}$ & $\begin{array}{c}0.382 \\
(0.064)\end{array}$ \\
\hline$\beta_{J D}$ & $\begin{array}{l}-0.136 \\
(0.055)\end{array}$ & $\begin{array}{l}-0.010 \\
(0.021)\end{array}$ & $\begin{array}{l}-0.019 \\
(0.008)\end{array}$ & $\begin{array}{l}-0.080 \\
(0.026)\end{array}$ & $\begin{array}{l}-0.006 \\
(0.012)\end{array}$ & $\begin{array}{l}-0.007 \\
(0.006)\end{array}$ & $\begin{array}{l}-0.769 \\
(0.185)\end{array}$ & $\begin{array}{l}-0.090 \\
(0.082)\end{array}$ & $\begin{array}{l}-0.091 \\
(0.041)\end{array}$ \\
\hline$\beta_{J W}$ & $\begin{array}{c}0.230 \\
(0.122)\end{array}$ & $\begin{array}{c}0.050 \\
(0.081)\end{array}$ & $\begin{array}{l}-0.075 \\
(0.067)\end{array}$ & $\begin{array}{c}0.090 \\
(0.033)\end{array}$ & $\begin{array}{c}0.043 \\
(0.029)\end{array}$ & $\begin{array}{l}-0.004 \\
(0.025)\end{array}$ & $\begin{array}{c}0.775 \\
(0.390)\end{array}$ & $\begin{array}{c}0.227 \\
(0.298)\end{array}$ & $\begin{array}{l}-0.289 \\
(0.271)\end{array}$ \\
\hline$\beta_{J M}$ & $\begin{array}{l}-0.271 \\
(0.177)\end{array}$ & $\begin{array}{l}-0.145 \\
(0.216)\end{array}$ & $\begin{array}{l}-0.116 \\
(0.245)\end{array}$ & $\begin{array}{l}-0.113 \\
(0.045)\end{array}$ & $\begin{array}{l}-0.076 \\
(0.058)\end{array}$ & $\begin{array}{l}-0.057 \\
(0.075)\end{array}$ & $\begin{array}{l}-1.319 \\
(0.589)\end{array}$ & $\begin{array}{l}-0.477 \\
(0.773)\end{array}$ & $\begin{array}{l}-0.034 \\
(0.918)\end{array}$ \\
\hline$R_{H A R-R V-C J}^{2}$ & 0.144 & 0.325 & 0.377 & 0.192 & 0.353 & 0.393 & 0.222 & 0.365 & 0.400 \\
\hline
\end{tabular}

Key: The table reports the OLS estimates for daily $(\mathrm{h}=1)$ and overlapping weekly $(\mathrm{h}=5)$ and monthly $(\mathrm{h}=22)$ HAR-RV-CJ volatility forecast regressions. All of the realized volatility measures are constructed from fiveminute returns spanning the period from January 1990 through December 2002, for a total of 3,213 daily observations. The weekly and monthly measures are the scaled sums of the corresponding daily measures. The significant daily jump and continuous sample path variability measures are based on equations (19) and (20), respectively, along with the staggered power variation measures in equations (22) and (23), using a critical value of $\alpha=0.999$. The standard errors reported in parentheses are based on a Newey-West/Bartlett correction allowing for serial correlation of up to order $5(\mathrm{~h}=1), 10(\mathrm{~h}=5)$, and $44(\mathrm{~h}=22)$, respectively. 
Figure 1A

Daily DM/\$ Realized Volatilities and Jumps
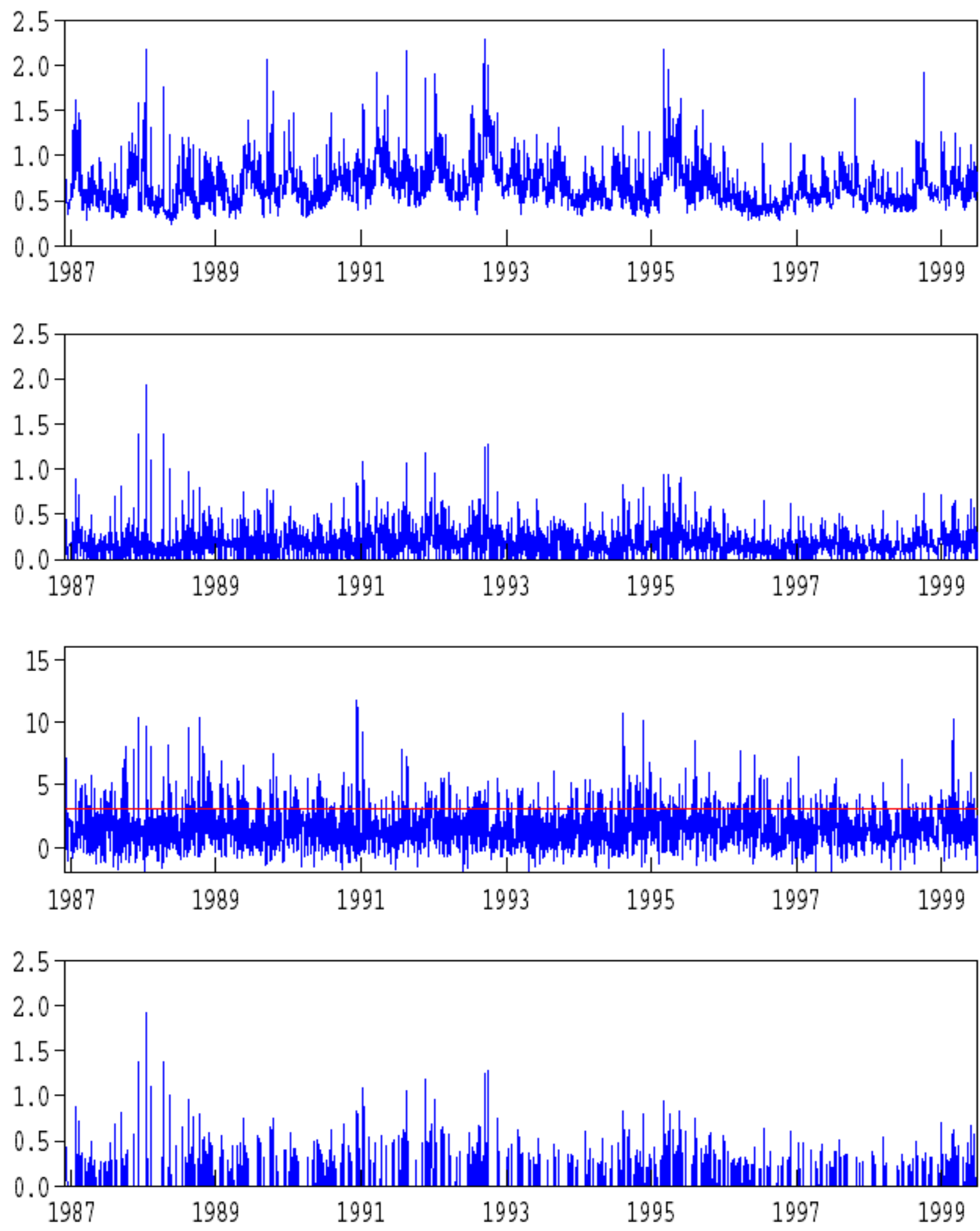

Key: The top panel shows daily realized volatility in standard deviation form, or $R V_{t}^{1 / 2}$. The second panel graphs the jump component defined in equation (8), $J_{t}^{1 / 2}$. The third panel shows the $Z_{1, t}(\Delta)$ statistic, with the 0.999 significance level indicated by the horizontal line. The bottom panel graphs the significant jumps corresponding to $\alpha=0.999$, or $J_{t, 0.999}^{1 / 2}$. See the text for details. 
Figure 1B

Daily S\&P500 Realized Volatilities and Jumps
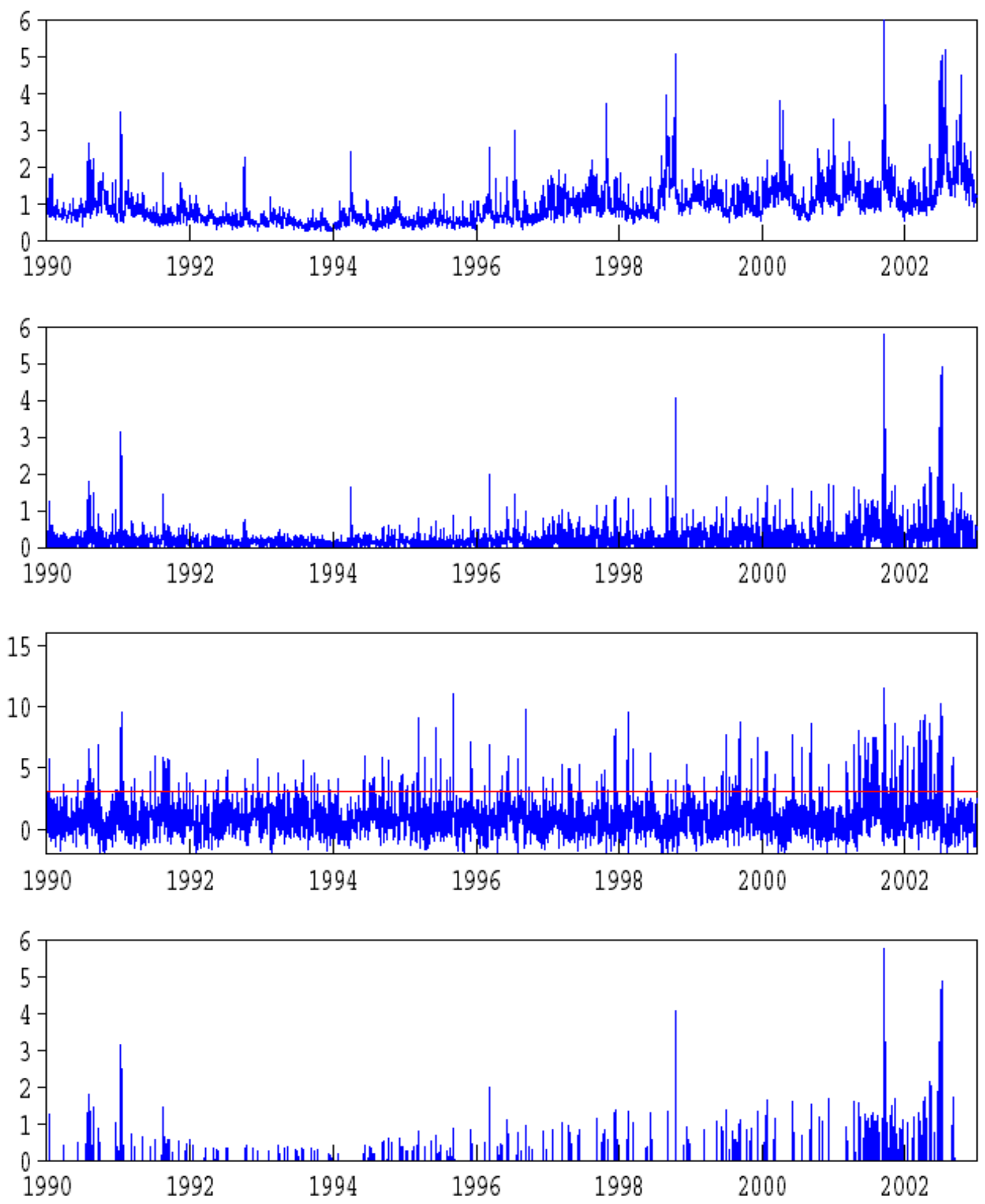

Key: The top panel shows daily realized volatility in standard deviation form, or $R V_{t}^{1 / 2}$. The second panel graphs the jump component defined in equation (8), $J_{t}^{1 / 2}$. The third panel shows the $Z_{1, t}(\Delta)$ statistic, with the 0.999 significance level indicated by the horizontal line. The bottom panel graphs the significant jumps corresponding to $\alpha=0.999$, or $J_{t, 0.999}^{1 / 2}$. See the text for details. 
Figure 1C

Daily U.S. T-Bond Realized Volatilities and Jumps
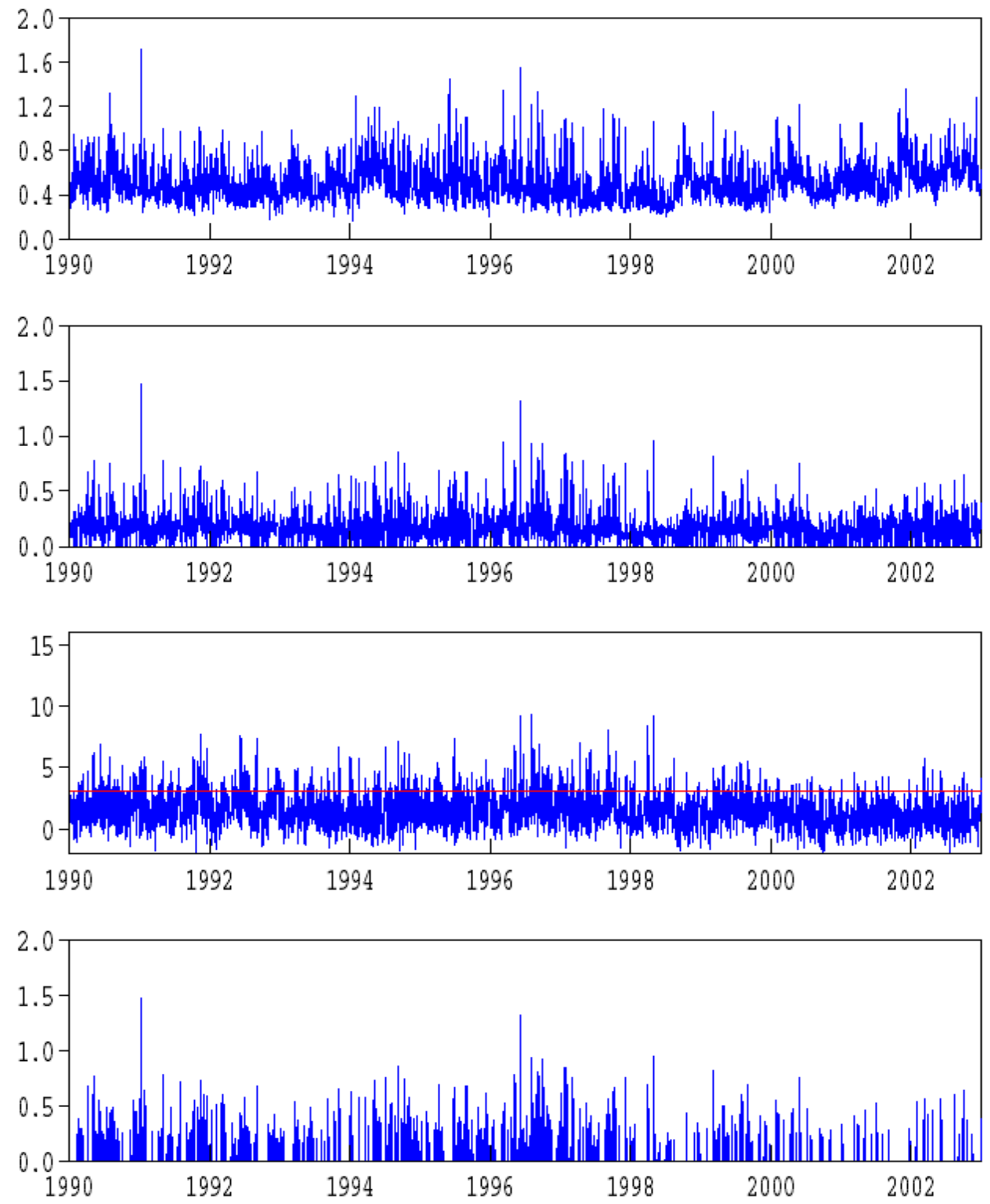

Key: The top panel shows daily realized volatility in standard deviation form, or $R V_{t}^{1 / 2}$. The second panel graphs the jump component defined in equation (8), $J_{t}^{1 / 2}$. The third panel shows the $Z_{l, t}(\Delta)$ statistic, with the 0.999 significance level indicated by the horizontal line. The bottom panel graphs the significant jumps corresponding to $\alpha=0.999$, or $J_{t, 0.999}^{1 / 2}$. See the text for details. 
Figure 2

Intraday Price Movements
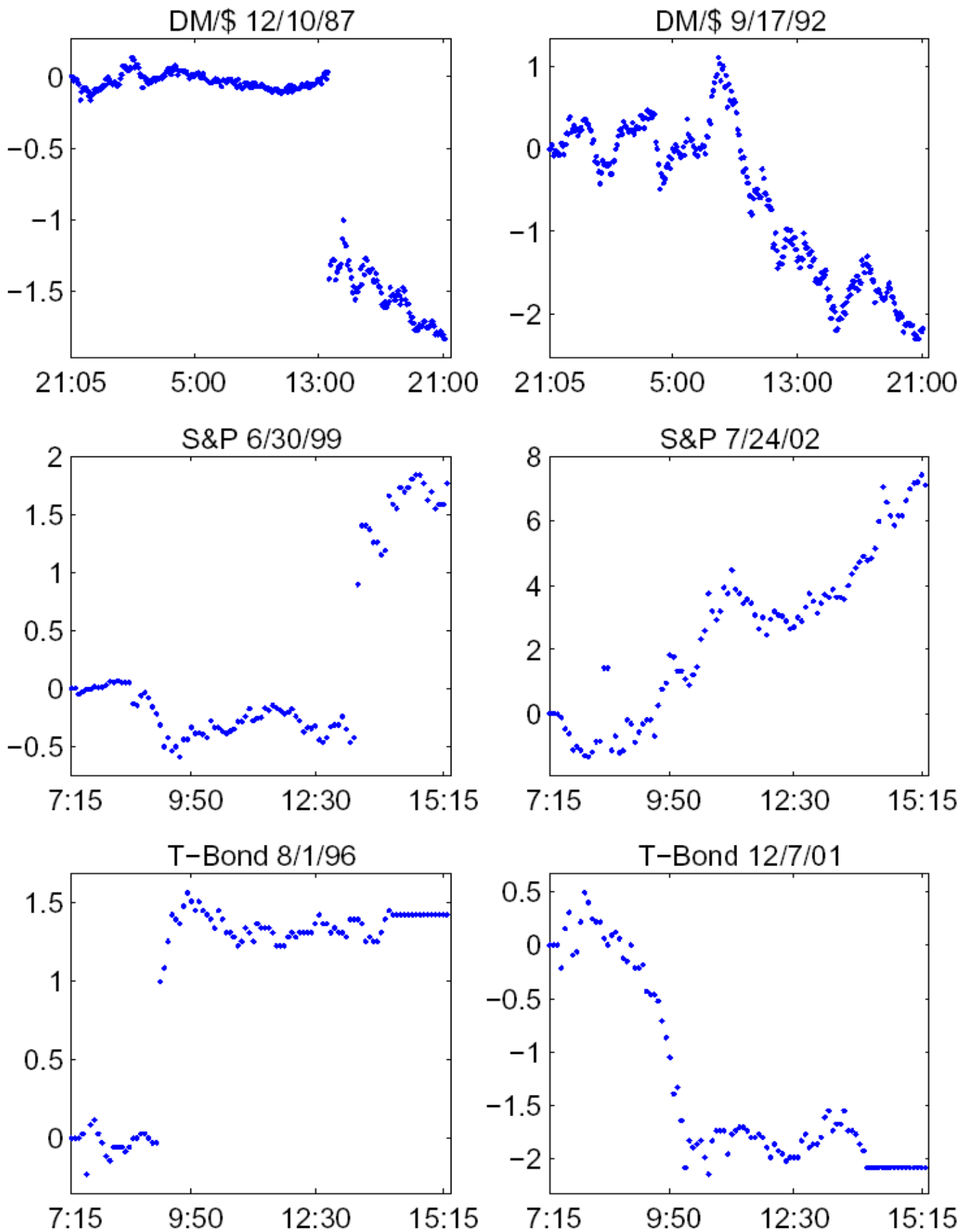

Key: The figure graphs the five-minute intraday price increments for days with large jump statistics $Z_{1, t}(\Delta)$ (left-side panels), and days with large daily price moves but numerically small jump statistics (right-side panels). 
Figure 3

Smoothed Jump Intensities and Jump Sizes
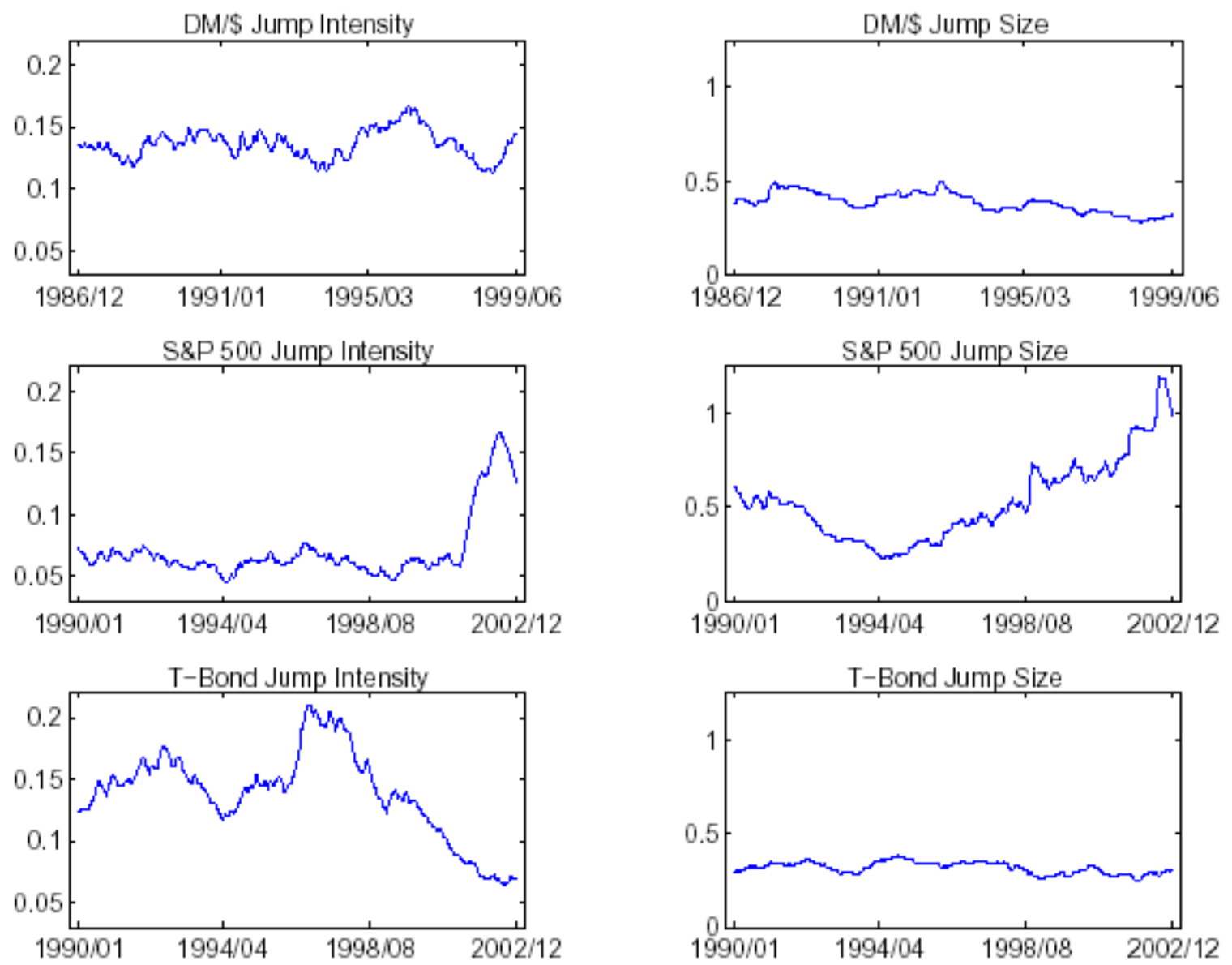

Key: The figure graphs the exponentially smoothed (with a smoothing parameter of 0.94 ) average monthly jump intensities and sizes for the significant jumps based on $\alpha=0.999$. The jump sizes are expressed in standard deviation form, or $J_{t, 0.999}^{1 / 2}$. 
Daily, Weekly, and Monthly DM/\$ Realized Volatilities and HAR-RV-CJ Forecasts
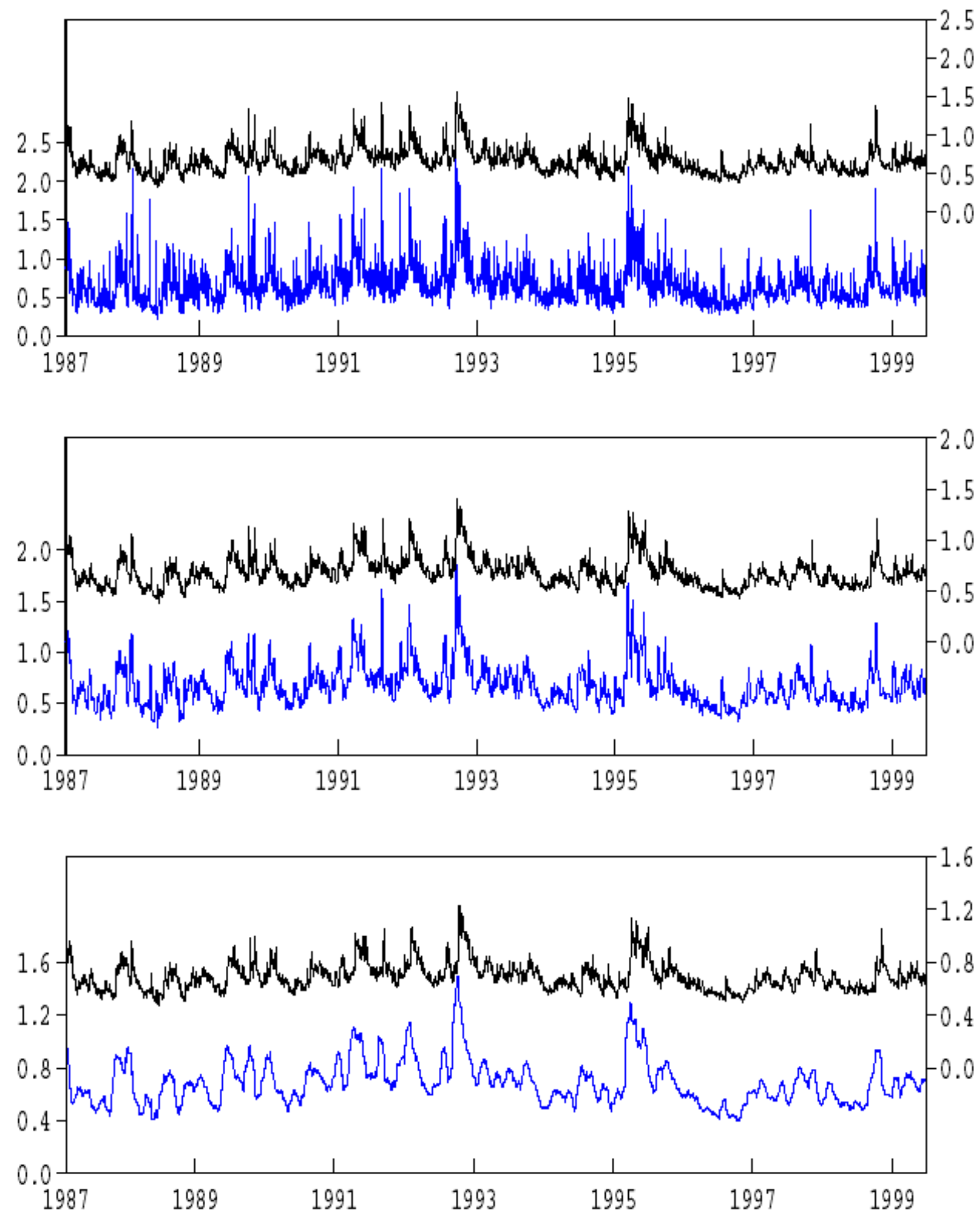

Key: The top, middle, and bottom panels show daily $(\mathrm{h}=1)$, weekly $(\mathrm{h}=5)$, and monthly $(\mathrm{h}=22)$ realized volatilities, $R V_{t, t+h}^{1 / 2}$ (left scale), and the corresponding forecasts from the HAR-RV-CJ model in standard deviation form in equation (27) (right scale). See the text for details. 
Figure 4B

Daily, Weekly, and Monthly S\&P500 Realized Volatilities and HAR-RV-CJ Forecasts
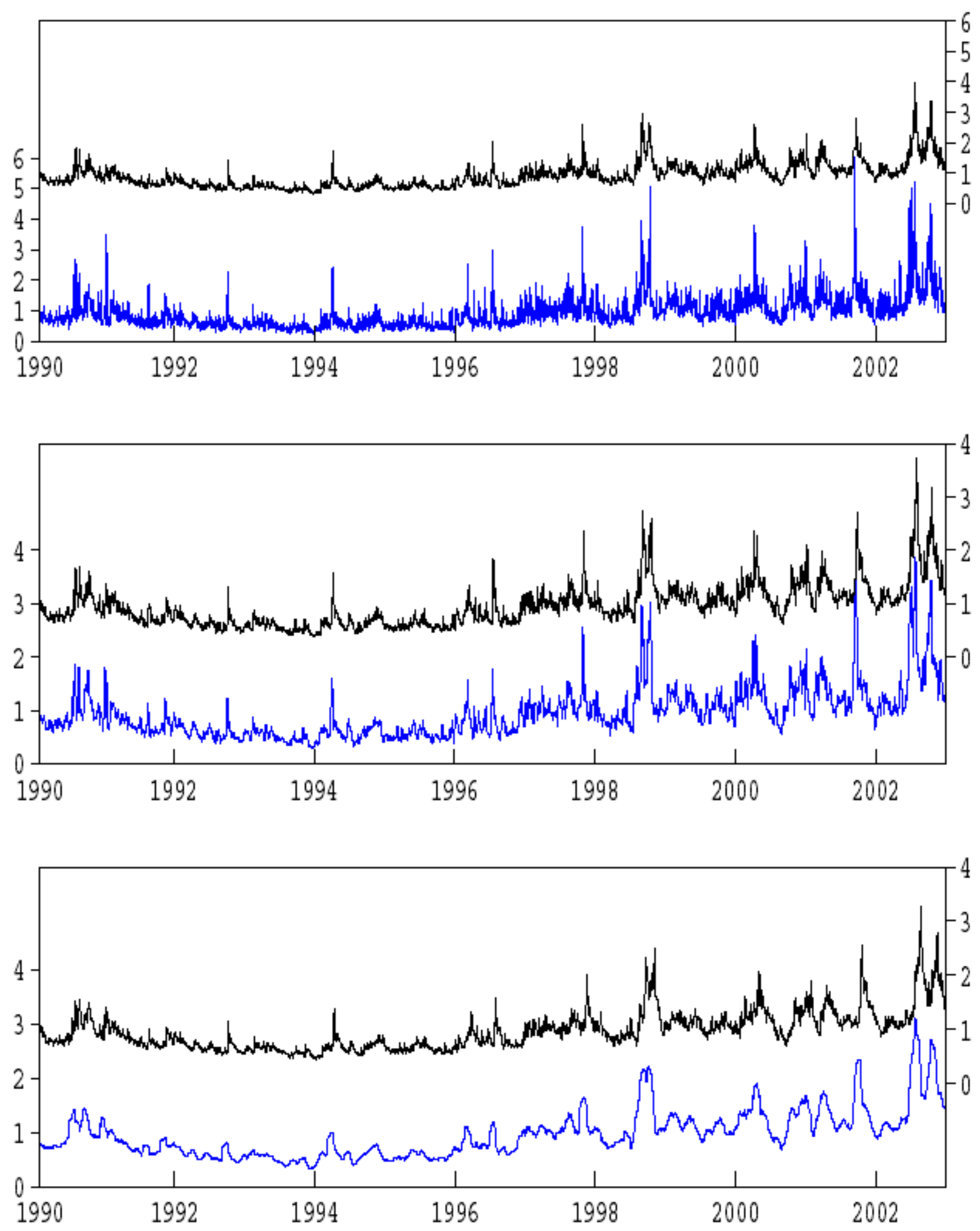

Key: The top, middle, and bottom panels show daily $(\mathrm{h}=1)$, weekly $(\mathrm{h}=5)$, and monthly $(\mathrm{h}=22)$ realized volatilities, $R V_{t, t+h}^{1 / 2}$ (left scale), and the corresponding forecasts from the HAR-RV-CJ model in standard deviation form in equation (27) (right scale). See the text for details. 
Figure 4C

Daily, Weekly, and Monthly U.S. T-Bond Realized Volatilities and HAR-RV-CJ Forecasts
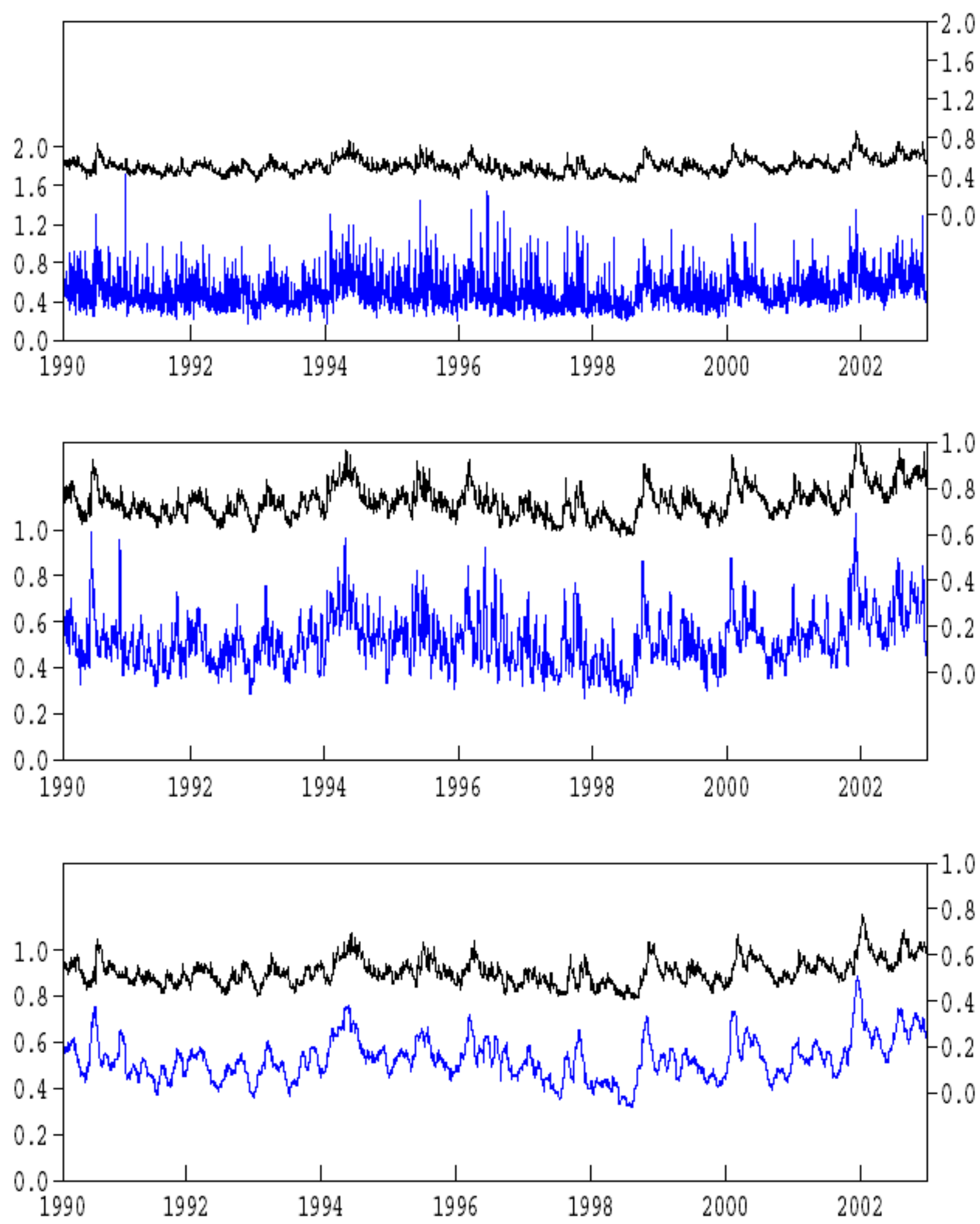

Key: The top, middle, and bottom panels show daily $(\mathrm{h}=1)$, weekly $(\mathrm{h}=5)$, and monthly $(\mathrm{h}=22)$ realized volatilities, $R V_{t, t+h}^{1 / 2}$ (left scale), and the corresponding forecasts from the HAR-RV-CJ model in standard deviation form in equation (27) (right scale). See the text for details. 